\title{
Going offshore or not: Where to generate hydrogen in future integrated energy systems?
}

\author{
Juan Gea-Bermúdez ${ }^{\mathrm{a}, *}$, Rasmus Bramstoft ${ }^{\mathrm{a}}$, Matti Koivisto ${ }^{\mathrm{b}}$, Lena Kitzing $^{\mathrm{b}}$, Andrés Ramos $^{\mathrm{c}}$ \\ ${ }^{a}$ Technical University of Denmark, Department of Management, Produktionstorvet, Bygning 424, 2800 Kongens Lyngby, Denmark \\ ${ }^{b}$ Technical University of Denmark, Department of Wind Energy, Roskilde, Denmark \\ ${ }^{c}$ Instituto de Investigación Tecnológica, Escuela Técnica Superior de Ingeniería, Universidad Pontificia Comillas, Madrid 28015, Spain
}

\begin{abstract}
Hydrogen can be key in the energy system transition. We investigate the role of offshore hydrogen generation in a future integrated energy system, and its interaction with other system elements. By performing energy system optimisation in a model application of the Northern-central European energy system and the North Sea offshore grid towards 2050, we find that offshore hydrogen generation may likely only play a limited role, and that offshore wind energy has higher value when sent to shore in the form of electricity. Forcing all hydrogen generation offshore would lead to increased energy system costs $\left(9-28 b €_{2016} /\right.$ year by 2045). Under the assumed scenario conditions, hydrogen generation - both onshore and offshore - follows solar PV generation patterns. Combined with hydrogen storage, this is the most cost-effective solution to satisfy future hydrogen demand. Overall, we find that the role of future offshore hydrogen generation should not simply be derived from minimizing costs for the offshore sub-system, but by also considering the value that such generation would create for the whole integrated energy system. Based on our results, a stronger political effort to promote the integration of offshore wind in onshore energy markets via electrical connection is called for.
\end{abstract}

Keywords: Offshore, Hydrogen, Optimisation, Sustainability Transition, Energy System, Modelling

\section{Introduction}

In relation to the Paris Agreement of 2015 and its corresponding long-term goals (The European Commission, 2015), the European Union (EU) signed the European Green Deal in 2019 (The European Commission, 2019). This document sets a strategy for the EU to transform the economy to achieve a sustainable future. The long-term vision of the $\mathrm{EU}$ is to achieve carbon neutrality by 2050 (The European Commission, 2020a). Previous studies have shown that sector coupling is important to achieve a cost-effective transition (Gea-Bermúdez et al., 2021b, Brown et al., 2018, Helgeson and Peter, 2020). This finding has been reflected in the EU strategy for energy system integration (The European Commission, 2020c). To facilitate system integration, the EU released its hydrogen $\left(\mathrm{H}_{2}\right)$ strategy in 2020 (The European Commission, 2020b), which promotes the generation of green $\mathrm{H}_{2}$, i.e. $\mathrm{H}_{2}$ generated from clean energy sources, to reduce greenhouse gas emissions across the energy sector. $\mathrm{H}_{2}$ can be used as fuel, energy carrier, storage, and feedstock, and hence, can provide large flexibility to the energy system.

The generation of large amounts of green $\mathrm{H}_{2}$ is expected to require massive deployment of variable renewable energy (VRE) in the system. The onshore deployment of VRE can be constrained by social acceptance, which can highly influence onshore wind installations (Egelund, 2010). To explore and promote offshore alternatives, the EU released its offshore renewable energy strategy in 2020 (The European Commission,

\footnotetext{
${ }^{*}$ Corresponding author

Email address: jgeab@dtu.dk (Juan Gea-Bermúdez)
}

2020d). Previous studies have found that it is cost-effective to develop some of the offshore development in advanced offshore grid configurations (Gea-Bermúdez et al., 2020, Konstantelos et al., 2017, Koivisto et al., 2019b). Furthermore, Denmark announced its intention to build an artificial energy island to deploy large-scale offshore wind and increase interconnection to other countries, considering generating green $\mathrm{H}_{2}$ on the island (DW, 2021) - a concept that could also become applicable to other countries. Underlying these developments, a general question remains: What will the role of offshore $\mathrm{H}_{2}$ generation be in future integrated energy systems?

Previous research on this field has focused on study cases analyzing the techno-economic feasibility of offshore wind, $\mathrm{H}_{2}$ generation and to some extent, its transportation. Dinh et al., 2020 developed an integrated model to assess the viability of $\mathrm{H}_{2}$ generation from dedicated offshore wind farms using an analytical approach. Hou et al., 2017 investigated investment potential of coupling offshore wind farms with different $\mathrm{H}_{2}$ system configurations. Babarit et al., 2018 investigated on the techno-economic feasibility of fleets of far offshore $\mathrm{H}_{2}$ producing wind energy converters. McDonagh et al., 2020 simulated the electricity and $\mathrm{H}_{2}$ generated by an offshore wind farm including and not including associated power-to-gas system. Franco et al., 2021 performed an assessment of offloading pathways for wind-powered offshore $\mathrm{H}_{2}$ generation, finding that the transport of the generated $\mathrm{H}_{2}$ to shore via pipelines seemed to be the best alternative.

The main contribution of this study is to investigate the role of offshore $\mathrm{H}_{2}$ generation in future integrated energy systems, 
as well as the interaction of this generation with other elements of the system, using a holistic energy system approach. To our knowledge, previous research on this topic has focused on techno-economic feasibility analysis and levelised cost of energy methods, and hence, the conclusions and policy recommendations obtained regarding the role of offshore $\mathrm{H}_{2}$ generation are highly limited since techno-economic analysis cannot easily capture the synergies and interactions between the different elements of the energy system. This paper addresses this important research gap.

The research in this paper is done by performing least-cost optimisation of capacity development and operation of the energy system of the European North Sea region towards 2050 from a socio-economic perspective. Several scenarios are optimised to investigate the socio-economic value of offshore $\mathrm{H}_{2}$ generation, and key factors that could influence such value.

The paper is structured as follows. Section 2 describes the methodology, data, and optimisation approach for the energy system model applied. The scenarios used in this paper are explained in Section 3. In Section 4, the results are presented and analyzed. In Section 5, the results are discussed, and conclusions and policy recommendations are presented in Section 6.

\section{Methodology and data}

We employ pre-existing energy model Balmorel for our analysis (Gea-Bermúdez et al., 2021b,) for which we have developed new features (highlighting the possibility for $\mathrm{H}_{2}$ transmission, and more detail in offshore grid modelling), as detailed below. The model and data used are open source (Balmorel community, 2021b, Balmorel community, 2021a) ${ }^{1}$.

\subsection{Balmorel}

\subsubsection{Generic model description}

The energy system model Balmorel (Wiese et al., 2018) is open-source (Balmorel community, 2021a), has a flexiblestructure, is deterministic, and has a bottom-up approach. The model has been developed greatly in the recent years to include more energy sectors (Gea-Bermúdez et al., 2021b), more details on hydrogen and electrofuels (Bramstoft et al., 2020, Lester et al., 2020, Jensen et al., 2020) and the capabilities to model in higher detail system operation (Gea-Bermúdez et al., 2021a). Balmorel is used to optimize capacity development and operation of the energy system towards 2050 to satisfy the energy demand of selected countries: France, the United Kingdom, Germany, Belgium, Denmark, Netherlands, Sweden, Finland, Norway, and Poland. The optimisation is done using hourly time resolution and from a socio-economic perspective. The spatial resolution used is based on existing bidding zones. Germany is split into different bidding zones to model intracountry bottlenecks. Bidding zones in the model are defined as regions, and are assumed to be copper plates for electricity transmission.

${ }^{1}$ The branch used for the data and code used in this paper is called "H2_Transport_update_2021_JGB" (last access 1st May 2021)
The energy system used includes the electricity, heat, and transport sectors (Figure 1). Decarbonisation of the transport sector towards 2050 is assumed in the scenarios.

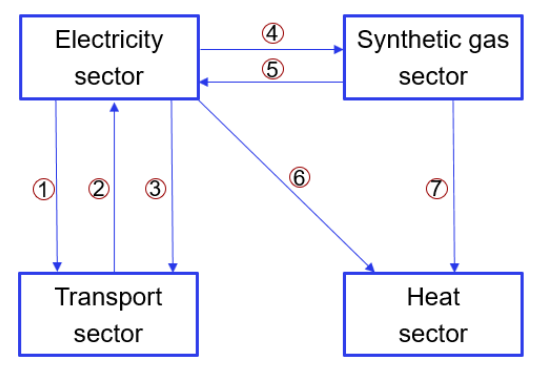

(1) Electricity grid to vehicle (2) Vehicle to electricity grid (3) Electricity to synthetic fuel generation

(4) Electricity to synthetic gas (5) Synthetic gas to electricity 6) Electricity to heat and Combined heat and Power (7) Synthetic gas to heat

Figure 1: Possible synergies between the sectors included in the model. Figure from Gea-Bermúdez et al., 2021b.

The objective function is to minimize discounted system costs (Wiese et al., 2018) (Equation 1). The different costs of each of the years $(y)$ studied are grouped in fixed costs $\left(c_{y}^{f o m}\right)$, variable costs $\left(c_{y}^{\text {vom }}\right)$, and investment costs $\left(c_{y}^{i n v}\right)$. All costs are annualised in the objective function. Investment costs are annualised with a socio-economic interest rate of $4 \%$ (Danish Energy Agency, 2021). This is done to make a fair comparison of the different technologies, since they can have different lifetimes. Variable costs include fuel costs, operation costs, and $\mathrm{CO}_{2}$ tax. The optimisation variables are technology investments (generation units, storage units, electricity transmission, $\mathrm{H}_{2}$ pipelines, district heating expansion), and technology operation on an hourly basis (energy generation, storage content, storage loading, energy trade, and electric vehicle (EV) operation). The storage content of hydro reservoirs without pumping is an exception and is modelled on a seasonal basis. Particularly, generation and storage unit mothballing is allowed, which is another variable, before reaching the end of their technical lifetime. Mothballing means that units can be inoperative during one year, to avoid paying the annual fixed costs, and become operative again in future years. The units are forced to decommission at the end of their technical lifetime. The decommissioning costs of exogenous units are not included. Future years are discounted using a discount rate of $4 \%$ (Danish Energy Agency, 2021), which is used to calculate the resulting discount factor $\left(D F_{y}\right)$ of each modelled year, to represent the socio-economic value of time.

$$
\min _{c_{y}^{\text {fom }}, c_{y}^{v o m}, c_{y}^{\text {inv }}} \sum_{y} D F_{y} \cdot\left(c_{y}^{\text {fom }}+c_{y}^{v o m}+c_{y}^{i n v}\right)
$$

Other key equations are commodity balances, technologyspecific operational constraints, storage balance, and resource potentials equations. Unit commitment is not considered in this study. However, the impact of this limitation on results is likely to be low given the high amount of flexibility options included (Poncelet et al., 2020).

\subsubsection{Energy system modelling}

Generation and storage technologies. Multiple generation and storage technologies are included in the optimisation and com- 
pete with each other: generation (dispatchable (hydro reservoirs, electric power-to-heat units (electric heaters, electric boilers, and heat pumps), fuel boilers, combined heat and power (CHP) and non-CHP thermal units, fuel cells, electrolysers, methanation-direct air capture) and non-dispatchable (wind onshore, wind offshore, solar PV, solar heating), storage (electric batteries, hydro pumping, pit thermal storage, heat water tanks, $\mathrm{H}_{2}$ tanks, offshore caverns for $\mathrm{H}_{2}$ storage). Technology data is mostly based on Danish Energy Agency, 2021 (Table 1). More details can be found in Gea-Bermúdez et al., 2021 b.

Electricity network. Electricity flow between regions is modelled with net transfer capacity (Gunkel et al., 2020b). Transmission losses per $\mathrm{km}$ distinguish between alternate current (AC) and direct current (DC) lines. Distribution losses for generation and storage technologies are defined depending on which part of the electric grid they are located in. Electricity transmission investment costs, calculated using the distance between the centroids of the modelled regions, are based on Nordic Energy Research and International Energy Agency, 2016 and Gea-Bermúdez et al., 2020. The lines are assumed to have a lifetime of 40 years (Danish Energy Agency, 2021). Protection or social compensation costs for the lines are not included. More details can be found in Gea-Bermúdez et al., $2021 b$.

Heat sector. The heat sector is divided into individual users (residential and tertiary sectors), industry, and district heating. The modelling of district heating is based on network scales inspired from Münster et al., 2012. District heating expansion is assumed to have a cost of $400 \mathrm{M} €_{2016} / \mathrm{MW}_{\text {th }}$ (Henning and Palzer, 2014) and a lifetime of 40 years (Danish Energy Agency, 2021). Individual users' modelling takes into account the end purpose of heat demand, i.e. space heating or hot water. Heat modelling in the industry sector is based on Danish Energy Agency, 2021, Rehfeldt et al., 2018, and Wiese and Baldini, 2018, and defines three different temperature needs: low (below $100^{\circ} \mathrm{C}$ ), medium $\left(100-500^{\circ} \mathrm{C}\right.$ ), and high (above $500^{\circ} \mathrm{C}$ ). More details about the modelling of the heat sector can be found in Gea-Bermúdez et al., 2021 b.

Synthetic gas. The synthetic gas sector includes the energy balance of synthetic natural gas $(\mathrm{SNG})$ and $\mathrm{H}_{2}$. An illustration of the modelling of the synthetic gas sector is shown in Figure 2.

The SNG modelling is based on Gea-Bermúdez et al., 2021b and its energy balance is defined on an hourly basis as an international market. SNG can be generated through methanationdirect air capture units, which consume heat, $\mathrm{H}_{2}$ and electricity. SNG can be used in gas units as a perfect replacement of fossil natural gas. The costs and constraints of natural gas networks, where SNG is assumed to be injected, are not included. This means that the generated $\mathrm{SNG}$ can be freely distributed around the modelled regions. The $\mathrm{CO}_{2}$ flows from $\mathrm{SNG}$ are ignored because it is assumed to be carbon neutral.

The $\mathrm{H}_{2}$ modelling is based on Gea-Bermúdez et al., 2021b, but it has been significantly improved to include more details. The $\mathrm{H}_{2}$ balance is defined for each region on an hourly basis. $\mathrm{H}_{2}$ trade between regions is allowed and constrained by the available pipeline capacity. In this paper, $\mathrm{H}_{2}$ can only be generated through alkaline water electrolysis units. Other type of electrolysers are not included for computational tractability. The transport of $\mathrm{H}_{2}$ is modelled with transmission pipelines assuming linear bi-directional flow. The existing $\mathrm{H}_{2}$ pipeline between regions is not included. The following assumptions are made based on Danish Energy Agency, 2021: $\mathrm{H}_{2}$ transmission pipes are assumed to have a lifetime of 50 years, an investment cost of $400 €_{2016} / \mathrm{km} / \mathrm{MW}_{\text {th }}$, and $\mathrm{H}_{2}$ transmission energy losses of $0.0022 \% / \mathrm{km}$ to keep the operating pressure of the $\mathrm{H}_{2}$ network, which is assumed to be 140 bar. The investment cost includes the cost of the compressors and additional equipment to keep the operating pressure. The energy required to compress the $\mathrm{H}_{2}$ generated from the electrolyser to inject it to the network is allocated to the electrolyser and it is assumed to be $2.1 \%, 1.7 \%$, and $1.5 \%$ for investments made in 2025, 2035 and 2045. The same data is assumed for offshore and onshore grid equipment (pipes, compressors, etc.) for simplicity. Other means of transporting $\mathrm{H}_{2}$, e.g. ships, liquid $\mathrm{H}_{2}$, etc., are not considered. Distribution $\mathrm{H}_{2}$ networks and the required equipment to deliver $\mathrm{H}_{2}$ to the consumption point are not included, but their corresponding losses are included (1.5\% of the exogenous demand based on Danish Energy Agency, 2021). The possibility to reconvert existing natural gas networks into $\mathrm{H}_{2}$ ones is not considered.

Fuel cells, methanation-direct air capture units, electrolysers and $\mathrm{H}_{2}$ storage are assumed to be connected to the $\mathrm{H}_{2}$ transmission network, and hence, are assumed to not incur into distribution losses. $\mathrm{H}_{2}$ storage units are assumed to operate at a similar pressure as the $\mathrm{H}_{2}$ transmission grid for simplicity. A round trip efficiency of $99 \%$ is assumed for all $\mathrm{H}_{2}$ storage technology types to acknowledge possible energy losses in the storing process.

Electrolysers invested offshore are assumed to be built with a reverse osmosis desalination plant, which incurs into additional electricity consumption ( $0.04 \mathrm{kWh}$ per ton of $\mathrm{H}_{2}$ generated) and capital expenditure ( $4280 €_{2016} / \mathrm{MW}_{\mathrm{e}}$ ) (IEA, 2019). Electrolysers built onshore can either be connected or not-connected to district heating networks. If they are built connected to district heating networks, their excess heat can be used in these networks, at the expense of incurring into additional capital expenditure related to the connection to the district heating network. Such cost is assumed to be $105000 €_{2016}$ for every $\mathrm{MW}_{\text {th }}$ of excess heat connected, and mainly corresponds to the cost of the heat exchanger. For every MW of electricity consumed in the electrolyser, a certain amount of thermal energy is generated as recoverable excess heat, which is the one that can be absorbed by the district heating network. This amount depends on the efficiency of the electrolyser and is based on Danish Energy Agency, 2021.

Exogenous $\mathrm{H}_{2}$ demand is assumed for industrial purposes and for the decarbonisation of the transport sector (Figure 3). The $\mathrm{H}_{2}$ demand for industrial purposes is inflexible and constant along the year, and its demand scenario is based on the European commission's 1.5TECH scenario (European Commission, 2018). The scenario for $\mathrm{H}_{2}$ demand for the decarbonisation of the transport sector, which is modelled as relatively 
Table 1: Investment costs development assumptions of selected large-scale technologies in $\mathrm{M} €_{2016} / \mathrm{MW}$ (M€ $€_{2016} / \mathrm{MWh}$ for storage). Other costs, like operational fixed costs, or variable fixed costs are not shown, but can be found in Balmorel community, 2021b. Costs for fuel cells and electrolysers are defined on the electrical side.

\begin{tabular}{|c|c|c|c|c|}
\hline Technology & 2025 & 2035 & 2045 & Source \\
\hline $\begin{array}{l}\text { Solar PV } \\
\text { (AC side) }\end{array}$ & 0.4200 & 0.3000 & 0.2600 & Danish Energy Agency, 2021 \\
\hline Onshore wind & 1.2728 & 1.1456 & 1.0539 & Danish Energy Agency, 2021 \\
\hline $\begin{array}{c}\text { Offshore wind radial } \\
\text { (nearshore, } \mathrm{AC}, \text { western Denmark) }\end{array}$ & 1.6609 & 1.5783 & 1.5140 & $\begin{array}{c}\text { Koivisto et al., 2019b, Danish Energy Agency, } 2021 \\
\text { EA Energy Analysis, 2020, EDMOnet-Bathymetry, } 2021\end{array}$ \\
\hline $\begin{array}{c}\text { Offshore wind radial } \\
\text { (far offshore, } \mathrm{AC} \text {, western Denmark) }\end{array}$ & 2.0662 & 1.8781 & 1.7379 & $\begin{array}{c}\text { Koivisto et al., 2019b, Danish Energy Agency, } 2021 \\
\text { EA Energy Analysis, 2020, EDMOnet-Bathymetry, } 2021\end{array}$ \\
\hline $\begin{array}{c}\text { Offshore wind radial } \\
\text { (far offshore, } \mathrm{DC} \text {, western Denmark) }\end{array}$ & 2.7208 & 2.4829 & 2.3139 & $\begin{array}{l}\text { Koivisto et al., 2019b, Danish Energy Agency, } 2021 \\
\text { EA Energy Analysis, 2020, EDMOnet-Bathymetry, } 2021\end{array}$ \\
\hline $\begin{array}{l}\text { Hub-connected offshore wind } \\
(20 \mathrm{~m} \text { depth, close to hub) }\end{array}$ & 2.1165 & 1.9098 & 1.7839 & $\begin{array}{l}\text { Koivisto et al., 2019b, Danish Energy Agency, } 2021 \\
\text { EA Energy Analysis, 2020, EDMOnet-Bathymetry, } 2021\end{array}$ \\
\hline $\begin{array}{l}\text { Hub-connected offshore wind } \\
(20 \text { m depth, far from hub) }\end{array}$ & 2.2025 & 1.9915 & 1.8656 & $\begin{array}{l}\text { Koivisto et al., 2019b, Danish Energy Agency, } 2021 \\
\text { EA Energy Analysis, 2020, EDMOnet-Bathymetry, } 2021\end{array}$ \\
\hline $\begin{array}{l}\text { Hub-connected offshore wind } \\
\text { (30 m depth, close to hub) }\end{array}$ & 2.2265 & 2.0098 & 1.8739 & $\begin{array}{c}\text { Koivisto et al., 2019b, Danish Energy Agency, } 2021 \\
\text { EA Energy Analysis, 2020, EDMOnet-Bathymetry, } 2021\end{array}$ \\
\hline $\begin{array}{l}\text { Hub-connected offshore wind } \\
\text { (30 m depth, far from hub) }\end{array}$ & 2.3125 & 2.0915 & 1.9556 & $\begin{array}{l}\text { Koivisto et al., 2019b, Danish Energy Agency, } 2021 \\
\text { EA Energy Analysis, 2020, EDMOnet-Bathymetry, } 2021\end{array}$ \\
\hline $\begin{array}{c}\text { Offshore hub } \\
\text { (platform and equipment) }\end{array}$ & 0.1860 & 0.1860 & 0.1683 & Koivisto et al., 2019b \\
\hline $\begin{array}{c}\text { Electrolyser onshore } \\
\text { (alkaline) }\end{array}$ & 0.6500 & 0.4500 & 0.3000 & Danish Energy Agency, 2021 \\
\hline $\begin{array}{c}\text { Electrolyser onshore } \\
\text { (alkaline, connected to district heating) }\end{array}$ & 0.6605 & 0.4605 & 0.3105 & Danish Energy Agency, 2021 \\
\hline $\begin{array}{c}\text { Electrolyser offshore } \\
\text { (alkaline, with osmosis plant) }\end{array}$ & 0.6505 & 0.4505 & 0.3005 & Danish Energy Agency, 2021, IEA, 2019 \\
\hline $\begin{array}{c}\text { Fuel cell } \\
\text { (solid oxide) }\end{array}$ & 1.5000 & 0.8000 & 0.6500 & Danish Energy Agency, 2021 \\
\hline $\begin{array}{c}\text { Lithium battery } \\
\text { (electricity storage) }\end{array}$ & 0.4105 & 0.3284 & 0.2463 & Lazard, 2017 \\
\hline $\begin{array}{c}\text { Pumped hydro } \\
\text { (electricity storage) }\end{array}$ & 0.2908 & 0.2908 & 0.2908 & Danish Energy Agency, 2021 \\
\hline $\begin{array}{c}\text { Steel tank } \\
\left(\mathbf{H}_{2} \text { storage }\right)\end{array}$ & 0.0570 & 0.0450 & 0.0270 & Danish Energy Agency, 2021 \\
\hline $\begin{array}{l}\text { Offshore cavern } \\
\left(\mathrm{H}_{2} \text { storage }\right)\end{array}$ & 0.0030 & 0.0020 & 0.0015 & Danish Energy Agency, 2021 \\
\hline
\end{tabular}




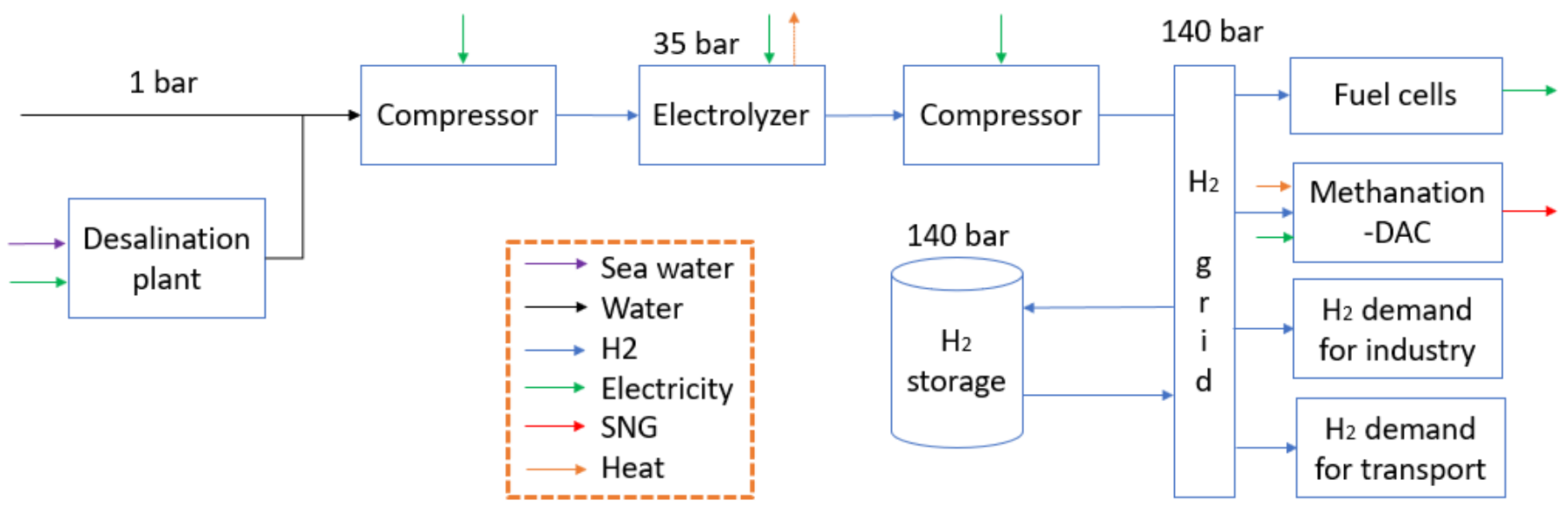

Figure 2: Illustration of synthetic gas sector modelling. Desalination plants are only relevant if electrolysers are built offshore. Heat coming out from the electrolysers can only be used if built in district heating networks. The $\mathrm{H}_{2}$ grid includes the required equipment (compressors, measuring stations, etc.) to keep an operating pressure of 140 bar. SNG stands for synthetic natural gas, and DAC for direct air capture.

inflexible demand, is explained later in this section.

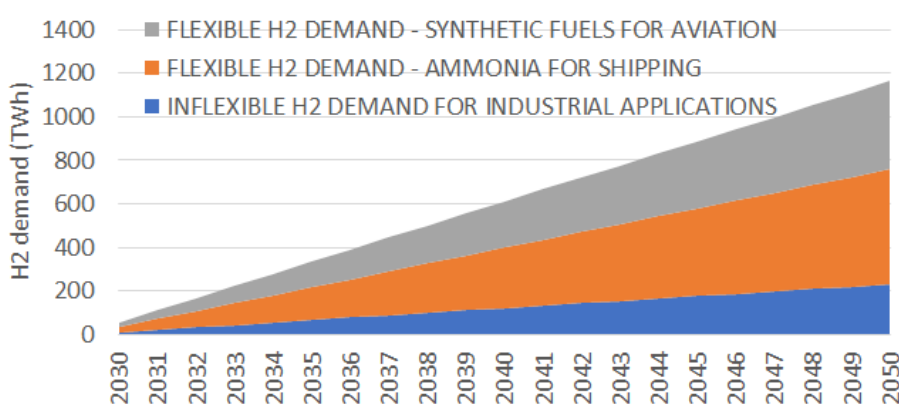

Figure 3: Annual $\mathrm{H}_{2}$ demand assumption split by type (TWh).

Transport sector. Decarbonisation of the transport sector demand towards 2050 is assumed and its modelling split into inflexible and flexible EVs, and demand for synthetic fuels for transport.

Inflexible EVs include the electrification of buses and rail transport that is not currently electrified based on Transport and Environment, 2018. They are modelled with exogenous time series in each region. The demand pattern is assumed constant for trains and time dependent for buses (Philip Swisher, 2020).

Road transport, excluding buses, is modelled as flexible EVs with virtual storage for each region using time series of daily patterns to represent the expected amount of EVs connected to the electricity network (Gunkel et al., 2020a). The number of EVs towards 2050, which is used to calculate the time series used, is not optimised but assumed. The data is taken from Philip Swisher, 2020. The virtual storage content, and the charging and discharging of the EVs are the variables the model optimises in the scenarios. EVs are divided into battery EVs and plug-in hybrid EVs. The use of plug-in hybrid EVs for vehicle-to-grid is not allowed. The hourly storage balance is the main equation of this technology. It is assumed that, for each type of EV, the level of the storage at the beginning of the season (in this paper week) must equal the one in the end. The charger capacity limits maximum charging, whereas inflexible charging limits minimum charging. The daily patterns for road transport assume low availability of the vehicles from the morning to the afternoon, since it is assumed that the vehicles are not connected to the grid during most working hours. EV charging is penalised with distribution grid losses and a charger loss. More details about the virtual storage method can be found in Gea-Bermúdez et al., 2021b.

The annual synthetic fuel demand required to decarbonise the shipping and aviation transport sectors of the studied countries is included in the scenarios and based on Transport and Environment, 2018. This demand is modelled as an increasing annual $\mathrm{H}_{2}$ demand towards 2050 that needs to be satisfied in each onshore region along the year. The hourly distribution along the year of this demand is optimized. The technologies that consume this $\mathrm{H}_{2}$ to generate the synthetic fuels, e.g. ammonia, are not included for tractability purposes. The hourly operation of these units is indirectly restricted though to take into account that these plants are likely to require high capacity factors to maximise their profitability. This is done by adding a constraint that establishes an upper limit to the peak-to-average ratio of the hourly $\mathrm{H}_{2}$ demand in each region. This factor is equivalent to defining a minimum average capacity factor per region, which in this paper is set to be $2 / 3$. The $\mathrm{H}_{2}$ demand has been calculated by applying an efficiency assumption of $62.5 \%$ to the electricity consumption data shown in Transport and Environment, 2018. This efficiency includes distribution losses, which cannot be captured otherwise in the model because distribution networks are not included. Because of adding this $\mathrm{H}_{2}$ demand, investments in biomass units are not allowed, since the generation of synthetic fuels is likely to require the use of a large share of the available biomass resources (Sims et al., 2010). The costs and challenges related to the transport of the biomass resources is not included. 
The default assumption is that the generation of synthetic fuels to decarbonise the transport sector (modelled as $\mathrm{H}_{2}$ demand) cannot be shifted to other regions. This implies that each onshore region needs to consume a certain amount of $\mathrm{H}_{2}$ along the year to generate synthetic fuels to satisfy their own demand for these fuels. $\mathrm{H}_{2}$ can be generated in any region, but it needs to be sent ultimately to the onshore regions. This assumption is changed in some of the scenarios and is explained in Section 3.

The capital and operational costs of all the different transportation means (cars, shipping, aviation, etc.) are not included.

Energy efficiency. The European Commission's energy efficiency target of $32.5 \%$ reduction of final energy consumption by 2030 (The European Commission, 2020a) is assumed to be achieved. The assumptions on exogenous electricity (excluding the transport sector which already includes efficiency measures) and heat demand development towards 2050 consider this efficiency target. Even though the European Commission uses the year 2007 as a reference for this target, we have used the year 2016 to make this calculation due to data availability limitations.

Wind and solar modelling. To represent that solar and wind resources are not uniform inside the studied countries, the modelling of wind and solar PV technologies is based on several resource grades as it was done in Gea-Bermúdez et al., 2020. The resource grades can differ in investable potential, costs, and time series. Particularly, radially-connected offshore wind power plants (OWPP) are split into three resource grades: near shore and far offshore connected with alternating current (AC), and far offshore connected with direct current. Hub-connected OWPP are explained later. OWPP costs have been updated to introduce the influence of water depth on foundation costs of offshore wind turbines using data from EDMOnet-Bathymetry, 2021 and EA Energy Analysis, 2020. The CorRES model is used to simulate wind and solar PV time series (Nuño et al., 2018, Koivisto et al., 2019a).

The national onshore wind potential for the scenarios (419 GW for the studied countries) is taken from Nordic Energy Research and International Energy Agency, 2016. This limit is relatively low, and aims to represent low social acceptance towards onshore wind. Potentials for radially-connected OWPP are based on Nordic Energy Research and International Energy Agency, 2016 and Koivisto and Gea-Bermúdez, 2018, and large-scale solar PV national potentials are based on Ruiz et al., 2019. More details about VRE modelling can be found in GeaBermúdez et al., 2021b.

Fuel price and $\mathrm{CO}_{2}$ tax. Fuel prices and $\mathrm{CO}_{2}$ tax development data towards 2050 comes from Nordic Energy Research and International Energy Agency, 2016. The $\mathrm{CO}_{2}$ tax triggers the decarbonisation of they system. The $\mathrm{CO}_{2}$ tax is assumed to be $29.8,90.4,120.6 €_{2016} /$ ton in 2025,2035 , and 2045 , respectively. No other tax is included.

Biofuel data is assumed to be carbon neutral and based on Flex4RES project, 2019.
Offshore grid modelling. The modelling and data of offshore power grids is built upon the work of Gea-Bermúdez et al., 2020 and Koivisto et al., 2019b. Introducing the possibility to build an offshore grid allows for multiple configurations of offshore infrastructure. An illustration of the possible configuration of offshore infrastructure allowed in this paper is shown in Figure 4. Offshore regions, which are modelled as individual regions (bidding zones), can then be used to generate and transport electricity and/or $\mathrm{H}_{2}$. Modelling offshore grids as individual bidding zones allows to capture possible congestion issues of the pipes and electrical interconnectors connected to the hubs. Along this paper, offshore regions are also interchangeably called hubs.

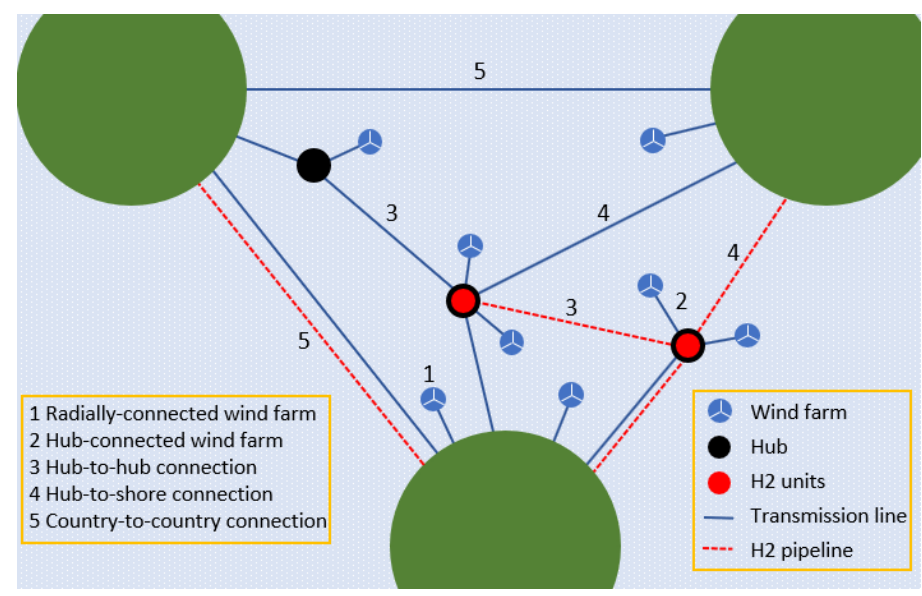

Figure 4: Possible configurations of offshore infrastructure allowed in the optimisations. Apart from hub platform, hubconnected wind farms and electricity and $\mathrm{H}_{2}$ DC interconnections, investments in electrolysers, $\mathrm{H}_{2}$ storage, and fuel cells are also allowed in the hubs.

The size of the offshore hub platform located in a particular offshore region is defined with its nameplate electrical capacity $\left(\right.$ cap platform $\left._{y, r}\right)$, which is modelled with Equation 2. The equation guarantees that, for each region $(r)$, year $(y)$, and time step $(t)$, the total size of the hub platform in an offshore region is larger or equal to the electricity demand of the different electrolysers $\left(d_{y, t, r}^{\text {electrolysers }}\right)$ located in the offshore region, and the sum of the electricity flows $\left(f_{y, t, r, r^{\prime}}\right)$ from the offshore region to other regions $\left(r^{\prime}\right)$, i.e. the total electricity export of the offshore region. This modelling reflects that the size of the offshore hub platform is constrained by the maximum electric power that is dealt with in the offshore region.

$$
\operatorname{cap}_{y, r}^{\text {platform }} \geq d_{y, t, r}^{\text {electrolysers }}+\sum_{r^{\prime}} f_{y, t, r, r^{\prime}}
$$

Hub-connected OWPP are split into two categories: closeto-hub and far-from-hub. This is done to model the influence of the size of the OWPP connected to the hub with respect to transmission investment costs, transmission losses, and wake losses. The reference size for a cluster of hub-connected OWPP, which is used to calculate the input parameters related to hubconnected OWPP, is $40 \mathrm{GW}$, with investments modelled in two 
steps: up to $20 \mathrm{GW}$, and above $20 \mathrm{GW}$. The capacity density of hub-connected OWPP is assumed to be $2.8 \mathrm{MW} / \mathrm{km}^{2}$. Investments up to $20 \mathrm{GW}$ are referred to as close-to-hub OWPP. Compared to close-to-hub OWPP, the capacity factors of far-fromhub OWPP are modelled as 19\% lower by downscaling the time series of close-to-hub OWPP. With close-to-hub OWPP modelled to have wake loss of $15 \%$, the total loss due to wakes is $23 \%$ when $40 \mathrm{GW}$ are installed, matching the efficiency reported in Volker et al., 2017. Compared to close-to-hub OWPP, far-from-hub OWPP are modelled with $36 \%$ higher transmission cost and $50 \%$ higher transmission loss due to longer cables from OWPP to hub. The transmission loss is based on Negra et al., 2006. Wake losses increase continuously when more GW are installed; however, to keep the model tractable, two steps of hub-connected investments are modelled.

\subsection{Optimisation approach}

For each scenario, the capacity development and operation optimisation is performed with limited intertemporal foresight (Gea-Bermúdez et al., 2020), following a two-year rolling horizon approach. This means that when planning 2025, 2035 is known, and so on.

Since the optimisations are complex, a reduced amount of time steps are used in the optimisation. These are selected using the approach described in Gea-Bermúdez et al., 2020. In this paper, we use 8 spread-over-the-year weeks, using Thursday, Friday, Saturday but with only 1 every 3 hours. This results in 192 time snapshopts per year. The time series are scaled using the methodology described in Gea-Bermúdez et al., 2020, which uses probability integral transformations to keep annual statistical properties of the time series. Weather data from multiple years is used in the scaling to improve VRE representation in the limited time steps used. This is done for all time series except for EV profiles, which are the average of threeconsecutive-hour time steps, and for seasonal hydro inflow, which is scaled linearly with respect to its corresponding average annual inflow.

Each scenario is obtained by performing two sets of optimisations. The first optimisation is done using linear programming (LP), whereas the second second optimisation is performed with mixed integer programming (MIP).

The objective of the first optimisation is to analyse the competition of all the technologies included in the model, whereas the objective of the second optimisation is to model in more detail economies of scale of offshore grids. This second optimisation, which is inspired by Gea-Bermúdez et al., 2020, avoids unrealistically small investments that can be a result from the linear programming optimisation, which cannot capture economies of scale. In the second optimisation, investments, mothballing, and/or decommissioning of the different technologies are forced from the first optimisation for almost all the technologies. The exceptions are hub platforms, hubconnected units (OWPP, $\mathrm{H}_{2}$ storage, fuel cells, and electrolysers), offshore transmission lines, and $\mathrm{H}_{2}$ pipes in the North Sea. Particularly for offshore transmission lines and $\mathrm{H}_{2}$ pipes, only those interconnections with investments in the first optimisation are allowed as possible investments in the second optimi-
Table 2: Economies of scale data assumptions for hubconnected electricity lines (Koivisto et al., 2019b) and $\mathrm{H}_{2}$ pipes (Danish Energy Agency, 2021) in the year 2035. Epsilon means a very small number. Fixed costs related to investments were only easily available for transmission lines, and for this reason, the costs for very small lines $\left(0.1 \mathrm{MW}_{\mathrm{e}}\right)$ are so high. The costs include the additional equipment to operate pipes and electricity lines, except for protection costs in electricity lines. Costs per $\mathrm{MW}_{\mathrm{e}}$ for hub-to-hub electricity lines are cheaper because converters are not needed since the hub and the lines are both assumed to be DC connected. In the linear programming optimisation, the costs used correspond to sizes of $1000 \mathrm{MW}_{\text {th }}$ for $\mathrm{H}_{2}$ pipes, and $2000 \mathrm{MW}_{\mathrm{e}}$ for electricity lines.

\begin{tabular}{|c|c|c|c|c|c|}
\hline \multicolumn{2}{|c|}{$\begin{array}{c}\text { Hub-connected } \\
\mathrm{H}_{2} \text { pipe }\end{array}$} & \multicolumn{2}{c|}{$\begin{array}{c}\text { Hub-to-hub } \\
\text { electricity line }\end{array}$} & \multicolumn{2}{c|}{$\begin{array}{c}\text { Hub-to-shore } \\
\text { electricity line }\end{array}$} \\
\hline $\begin{array}{c}\text { Capacity } \\
\left(\mathrm{MW}_{\text {th }}\right)\end{array}$ & $\begin{array}{c}\text { Investment cost } \\
\left(€_{2016} / \mathrm{MW}_{\text {th }} / \mathrm{m}\right)\end{array}$ & $\begin{array}{c}\text { Capacity } \\
\left(\mathrm{MW}_{\mathrm{e}}\right)\end{array}$ & $\begin{array}{c}\text { Investment cost } \\
\left(€_{2016} / \mathrm{MW}_{\mathrm{e}} / \mathrm{m}\right)\end{array}$ & $\begin{array}{c}\text { Capacity } \\
\left(\mathrm{MW}_{\mathrm{e}}\right)\end{array}$ & $\begin{array}{c}\text { Investment cost } \\
\left(€_{2016} / \mathrm{MW}_{\mathrm{e}} / \mathrm{m}\right)\end{array}$ \\
\hline epsilon & 3.7 & epsilon & 0 & epsilon & 0 \\
\hline 250 & 1.6 & 0.1 & 8157.3 & 0.1 & 14094.7 \\
\hline 500 & 0.7 & 300 & 2.7 & 700 & 2.0 \\
\hline 1000 & 0.4 & 1000 & 1.4 & 1000 & 1.7 \\
\hline 6000 & 0.2 & 2000 & 1.1 & 2000 & 1.4 \\
\hline 50000 & 0.2 & 50000 & 1.1 & 50000 & 1.4 \\
\hline
\end{tabular}

sation. Economies of scale are modelled in hubs, and offshore transmission lines and $\mathrm{H}_{2}$ pipes in the North Sea (Table 2). All this is done to simplify the second optimisation.

\section{Scenarios}

This paper aims at understanding the potential role of $\mathrm{H}_{2}$ generation towards 2050 in a European context, and the interaction of this generation with other elements of the system. For this reason, several scenarios are designed (Figure 5). Analysing different scenarios is of great importance to obtain meaningful insight considering the great uncertainty regarding key input data and modelling assumptions.

The central scenario of this paper is BASE. The rest of the scenarios are derived from this one. In the BASE scenario, all the technologies mentioned in Section 2 are included, except for offshore caverns for $\mathrm{H}_{2}$ storage.

To understand the influence on the energy system of forcing all $\mathrm{H}_{2}$ generation in the system to take place in offshore hubs, scenarios OFFH2 and OFFH2-HUB4H2 are created. Compared to scenario BASE, investments in electrolysers built onshore are forbidden in these two scenarios. Scenario OFFH2HUB4H2 restricts further the energy system with respect to scenario OFFH2 by forbidding hub-to-shore electricity connection. This means that all the electricity generated in the hubs has to be used to generate $\mathrm{H}_{2}$. The analysis of forbidding electrical connection of potential large-scale is of interest considering the potential technical issues related to the integration of large-scale hubs in the onshore network.

The BASE scenario assumes 1) that onshore electrolysers can be connected to district heating networks, 2) that it is not possible to use existing offshore caverns for storage of $\mathrm{H}_{2}$, and 3 ) that a fast decrease of electrolyser costs will take place towards 2050. All these assumptions reduce the value of offshore 


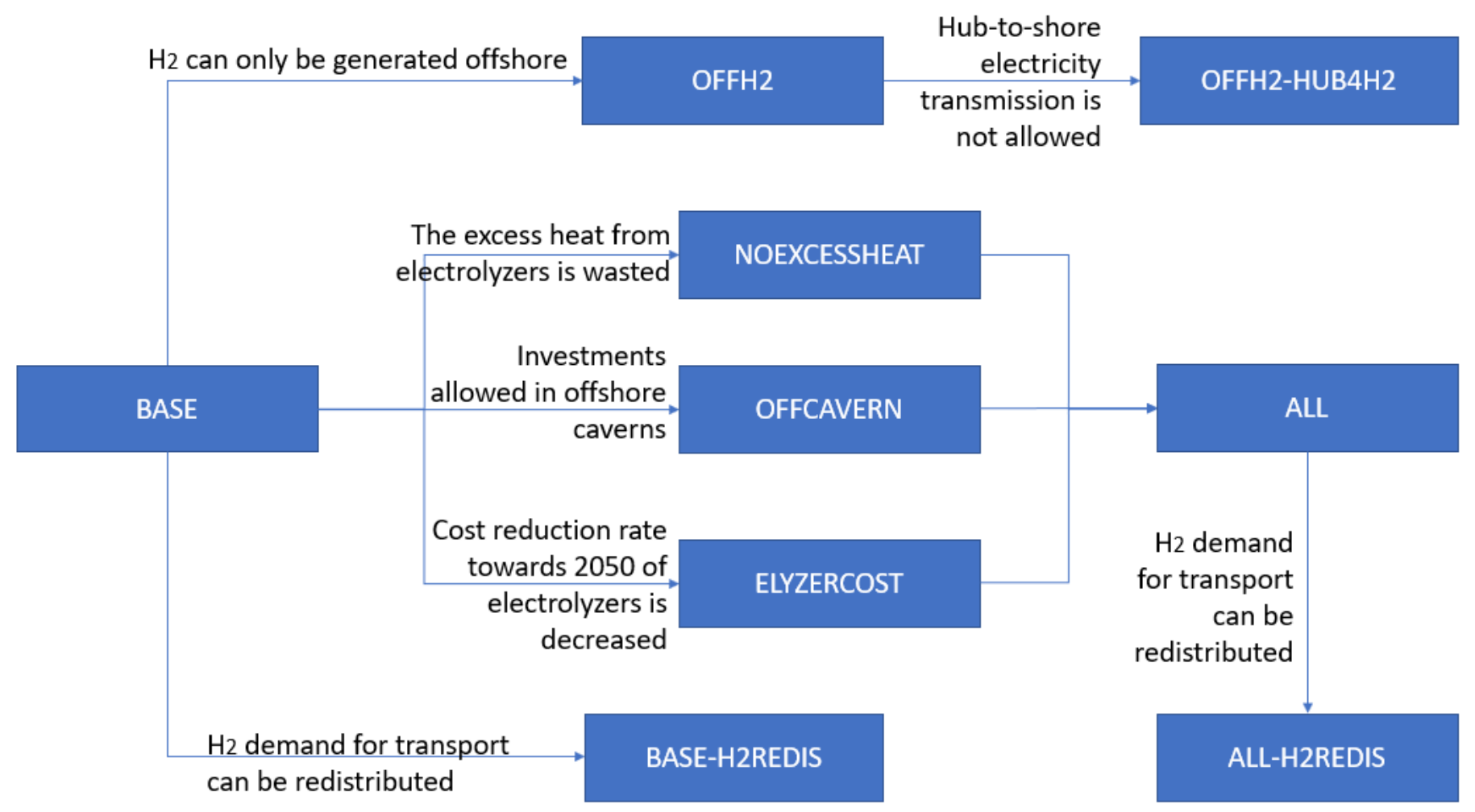

Figure 5: Difference between modelling assumptions in the different scenarios.

$\mathrm{H}_{2}$ generation and are not free from controversy and/or uncertainty. Scenarios NOEXCESSHEAT, OFFCAVERN, and ELYZERCOST are designed to dig into these selected uncertainties to analyse to which degree offshore $\mathrm{H}_{2}$ generation is affected by them. Other uncertainties like wind and solar PV technology development, $\mathrm{H}_{2}$ pipeline costs, or $\mathrm{H}_{2}$ storage efficiency could also be of interest but are excluded to reduce the number of scenarios. Scenario NOEXCESSHEAT includes the extreme case of assuming that the electrolysers built onshore cannot be built connected to district heating networks, leading to the waste of their excess heat. Scenario OFFCAVERN allows for the possibility to invest in cheap offshore caverns to store $\mathrm{H}_{2}$. Scenario ELYZERCOST assumes a lower cost reduction rate towards 2050 of the specific investment cost of the electrolysers (Table 3). The assumptions of these three scenarios are combined in scenario ALL, which aims to analyse the potential synergies between all these modifications.

In most of the scenarios, it is assumed that the required generation of synthetic fuels to decarbonise aviation and shipping sector takes place in each region. The generation of synthetic fuels for this purpose is modelled as $\mathrm{H}_{2}$ demand, as explained in Section 2. This means that each region needs to consume a given amount of $\mathrm{H}_{2}$ along the year to generate synthetic fuels to satisfy their own demand for these fuels. However, an alternative to this assumption could be to concentrate the generation of synthetic fuels in a few regions, and then export these fuels. With this idea in mind, in scenarios BASE-H2REDIS and ALL-H2REDIS, compared to BASE and ALL scenarios re-
Table 3: Specific investment cost for electrolysers installed onshore $\left(\mathrm{M} €_{2016} / \mathrm{MW}\right)$. Electrolysers built offshore or connected to district heating networks have additional investment costs.

\begin{tabular}{|c|c|c|}
\hline Year & $\begin{array}{c}\text { Base cost reduction } \\
\text { development }\end{array}$ & $\begin{array}{c}\text { Slower cost reduction } \\
\text { development }\end{array}$ \\
\hline 2025 & 0.65 & 0.65 \\
\hline 2035 & 0.45 & 0.565 \\
\hline 2045 & 0.3 & 0.48 \\
\hline
\end{tabular}

spectively, we allow for full redistribution of the $\mathrm{H}_{2}$ demand required to generate synthetic fuels. The costs, challenges, and required infrastructure associated to the trade of the resulting synthetic fuels is not modelled, and hence, ignored. Therefore, the results from these scenarios are likely to provide an optimistic view of how synthetic fuel generation could be.

\section{Results}

This section summarises the results obtained from the optimisations.

\subsection{Towards an interconnected decarbonised energy system}

The increasing $\mathrm{CO}_{2}$ price assumption towards 2050, together with the assumed transformation of the transport sector, leads to a massive electrification of the entire energy system towards 
2050. Such electrification increases the role of wind and solar PV generation (Figure 6). By 2045 in scenario BASE, wind and solar PV generation accounts for $83 \%$ of the total electricity generation mix (50\% wind and $33 \%$ solar PV), with offshore wind accounting for $62 \%$ of total wind generation, being $50 \%$ of it hub-connected. Offshore wind increases its importance from 2035 onward, when the best onshore wind locations have already been used. In the scenarios where $\mathrm{H}_{2}$ generation is forced to take place offshore, the contribution of hub-connected wind is much higher.

The scenarios also show strong reinforcement of the electricity grid towards 2050, which contributes to the integration of VRE. The accumulated investments by 2045 in electricity interconnectors varies between $110-161 \mathrm{TW}_{\mathrm{e}} \mathrm{km}$ in the scenarios, which corresponds to 2.4-3.5 times the exogenous interconnectors assumed to exist by 2025 . Hub-connected electricity interconnectors by 2045 correspond to $43-54 \%$ of the accumulated $\mathrm{TW}_{\mathrm{e}} \mathrm{km}$ endogenous investments in the scenarios, except for scenario OFFH2-HUB4H2, where it only accounts for $2 \%$. The investments in interconnectors in scenario OFFH2HUB4H2 correspond to hub-to-hub lines, since hub-to-shore investments were not allowed in this scenario.

The development of $\mathrm{H}_{2}$ pipelines is also remarkable. The accumulated investments by 2045 in $\mathrm{H}_{2}$ pipelines varies between 6-108 $\mathrm{TW}_{\mathrm{th}} \mathrm{km}$ in the scenarios. The variability in accumulated $\mathrm{H}_{2}$ pipeline investments is larger than the electrical interconnectors's one. Hub-connected $\mathrm{H}_{2}$ pipelines by 2045 correspond to $6-52 \%$ of the accumulated $\mathrm{TW}_{\mathrm{th}} \mathrm{km}$ endogenous investments in the scenarios.

\section{2. $\mathrm{H}_{2}$ generation is preferred onshore over offshore}

The contribution of offshore $\mathrm{H}_{2}$ generation in the BASE scenario towards 2050 is very limited: $0 \%$ in 2035 and $2 \%$ in 2045 (Table 4). Not being able to utilise the excess heat from electrolysers (scenario NOEXCESSHEAT) or introducing the possibility to use offshore caverns as $\mathrm{H}_{2}$ storage (scenario OFFCAVERN) significantly impacts the share of offshore $\mathrm{H}_{2}$ generation, reaching in both scenarios $10 \%$ of the total $\mathrm{H}_{2}$ generation by 2045. Decreasing the cost reduction rate of electrolysers (scenario ELYZERCOST) has a much lower impact on offshore $\mathrm{H}_{2}$ generation, reaching 3\% of total $\mathrm{H}_{2}$ generation by 2045, which suggests that the costs related to the generation of electricity to feed the electrolysers are likely to be more important than the capital expenditure of the electrolysers. The combination of all these changes in scenario ALL leads to the highest contribution of offshore $\mathrm{H}_{2}$ generation by 2045 , i.e. $26 \%$. These results show that onshore $\mathrm{H}_{2}$ generation is, overall, preferred over offshore generation from a socio-economic point of view.

\subsection{Solar PV patterns drives $\mathrm{H}_{2}$ generation both offshore and onshore}

Generating $\mathrm{H}_{2}$ in the electrolysers following the solar PV pattern, combined with $\mathrm{H}_{2}$ storage, is the most cost-effective way to satisfy $\mathrm{H}_{2}$ demand. This does not mean that solar PV is the only source of energy used to feed the electrolysers, since the wind generation in the system in the hours of the middle of the day is far from being negligible. In scenario BASE in 2045, the total generation of wind in the modelled hours of the middle of the day (H10, H13, and H16) is $51 \%$ of the total solar PV generation.

The solar PV pattern influences the generation of $\mathrm{H}_{2}$ everywhere, even in the locations without solar PV generation (offshore hubs and the regions in Norway, Sweden, and Finland) because the system becomes highly interconnected electrically. The solar PV pattern leads to low electricity prices in all the regions that are electrically interconnected, favoring onshore $\mathrm{H}_{2}$ generation since it is onshore where the exogenous $\mathrm{H}_{2}$ demand is assumed to be located, reducing the need for $\mathrm{H}_{2}$ transport. Solar PV generation influences $\mathrm{H}_{2}$ generation in the hubs when connected electrically to shore (Figure 7). The solar pattern leads to less need for exporting electricity from the hubs in the hours of the middle of the day, reducing the net export from the hubs in these hours. The electricity that is not exported in these hours is then used to generate $\mathrm{H}_{2}$, or curtailed, as illustrated in the hourly energy balance of electricity of the so-called in this paper central Norwegian hub in 2045 of Figure 8. When the hubs are not allowed to be connected electrically to shore (scenario OFFH2-HUB4H2), then the generation of $\mathrm{H}_{2}$ follows the wind pattern instead of the solar one (grey line in Figure 7).

\subsection{Curtailment follows the solar pattern}

Wind and solar PV curtailment concentrates in the hours of the middle of the day and in the middle of the year, i.e. when solar PV generation is highest (Figure 9). The energy curtailed in 2045 in the scenarios varies between 135-183 TWh, and the curtailment share with respect to total available wind and solar PV generation between 3-4\%. Offshore wind is the technology which sees most of the curtailment in the scenarios as a result of cost minimisation, since it is assumed that the operational cost of offshore wind farms is higher than solar PV's or onshore wind's. Offshore wind curtailment by 2045 corresponds to 4$6 \%$ of total available offshore wind generation in the scenarios.

\section{5. $\mathrm{H}_{2}$ storage is key to integrate solar PV generation}

Generating $\mathrm{H}_{2}$ with the electrolysers following the solar PV pattern requires the extensive use of $\mathrm{H}_{2}$ storage to distribute the $\mathrm{H}_{2}$, since the $\mathrm{H}_{2}$ demand is modelled rather inflexible. The loading of $\mathrm{H}_{2}$ storage, regardless of its type, takes place in the middle of the day, and the unloading, in the rest of the hours (Figure 10). Storage is mostly used to deal with daily patterns, however, when cheap $\mathrm{H}_{2}$ storage is allowed (offshore caverns) then part of the $\mathrm{H}_{2}$ is also distributed seasonally.

$\mathrm{H}_{2}$ storage also plays a role in the need for $\mathrm{H}_{2}$ pipeline capacity, by reducing the peak of the transported $\mathrm{H}_{2}$ flows, and leading to lower invested pipeline capacity. This purpose is illustrated in Figures 11 and 12. Figure 11 shows how the hubs have, in general, a much higher electrolyser capacity than $\mathrm{H}_{2}$ transmission pipeline capacity, which becomes feasible due to $\mathrm{H}_{2}$ storage. Figure 12 shows how electrolyser capacity in the hub is higher than the capacity of the $\mathrm{H}_{2}$ pipes on the map, and the impact of considering economies of scale with mixed integer programming, which eliminates numerous small pipes and 


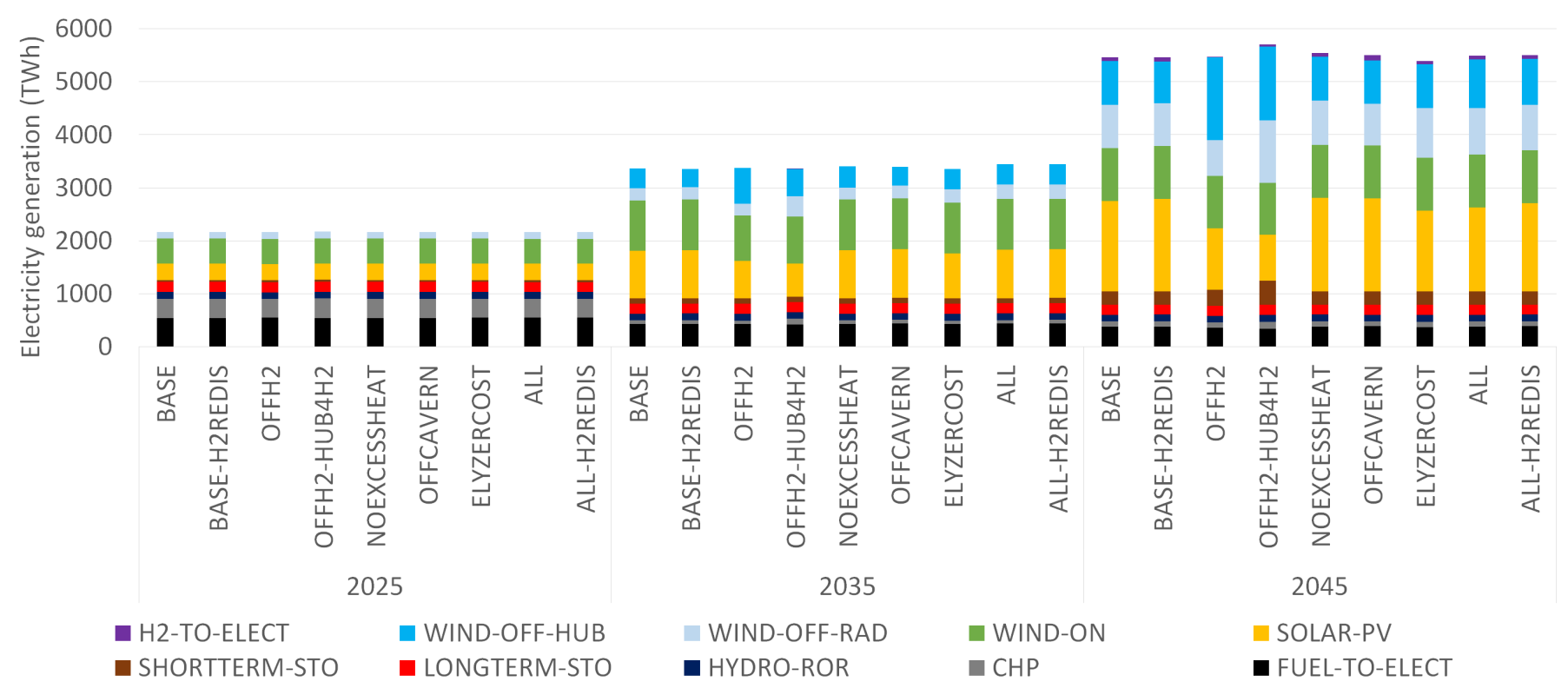

Figure 6: Electricity generation per year and scenario split by technology type. Long-term storage includes hydro reservoirs with hydro inflow, and short-term storage aggregates electric batteries (including flexible electric vehicles) and hydro pumping.

Table 4: Summary of key results per commodity for selected years. The units relate to the corresponding commodity.

\begin{tabular}{|c|c|c|c|c|c|c|c|c|c|c|c|c|c|c|c|c|}
\hline \multirow{3}{*}{ Scenario } & \multicolumn{8}{|c|}{ Electricity } & \multicolumn{8}{|c|}{$\mathrm{H}_{2}$} \\
\hline & \multicolumn{2}{|c|}{$\begin{array}{c}\text { Total } \\
\text { demand } \\
\text { (TWh) }\end{array}$} & \multicolumn{2}{|c|}{$\begin{array}{l}\text { Hub-connected } \\
\text { electrolyser } \\
\text { demand } \\
\text { (TWh) }\end{array}$} & \multicolumn{2}{|c|}{$\begin{array}{l}\text { Hub-connected } \\
\text { wind } \\
\text { generation } \\
\text { (TWh) }\end{array}$} & \multicolumn{2}{|c|}{$\begin{array}{l}\text { Hub-connected } \\
\text { wind } \\
\text { capacity } \\
(\text { GW })\end{array}$} & \multicolumn{2}{|c|}{$\begin{array}{c}\text { Total } \\
\text { demand } \\
\text { (TWh) }\end{array}$} & \multicolumn{2}{|c|}{$\begin{array}{l}\text { Hub-connected } \\
\text { electrolyser } \\
\text { generation } \\
\text { (TWh) }\end{array}$} & \multicolumn{2}{|c|}{$\begin{array}{c}\text { Share of } \\
\text { hub-connected } \\
\text { electrolyser } \\
\text { generation in } \\
\text { total demand }\end{array}$} & \multicolumn{2}{|c|}{$\begin{array}{l}\text { Hub-connected } \\
\text { electrolyser } \\
\text { capacity } \\
\text { (GW) }\end{array}$} \\
\hline & 2035 & 2045 & 2035 & 2045 & 2035 & 2045 & 2035 & 2045 & 2035 & 2045 & 2035 & 2045 & 2035 & 2045 & 2035 & 2045 \\
\hline BASE & 3259 & 5220 & 0 & 30 & 373 & 827 & 82 & 180 & 333 & 1054 & 0 & 21 & $0 \%$ & $2 \%$ & 0 & 10 \\
\hline BASE-H2REDIS & 3258 & 5209 & 0 & 13 & 346 & 790 & 77 & 173 & 332 & 1049 & 0 & 9 & $0 \%$ & $1 \%$ & 0 & 4 \\
\hline OFFH2 & 3277 & 5171 & 500 & 1308 & 680 & 1567 & 147 & 338 & 336 & 918 & 336 & 918 & $100 \%$ & $100 \%$ & 63 & 249 \\
\hline OFFH2-HUB4H2 & 3251 & 5254 & 502 & 1379 & 508 & 1393 & 111 & 288 & 338 & 962 & 338 & 962 & $100 \%$ & $100 \%$ & 64 & 185 \\
\hline NOEXCESSHEAT & 3307 & 5294 & 74 & 156 & 404 & 831 & 89 & 180 & 334 & 1043 & 49 & 109 & $15 \%$ & $10 \%$ & 9 & 36 \\
\hline OFFCAVERN & 3295 & 5256 & 10 & 149 & 353 & 816 & 77 & 174 & 336 & 1096 & 7 & 105 & $2 \%$ & $10 \%$ & 2 & 64 \\
\hline ELYZERCOST & 3250 & 5140 & 0 & 35 & 384 & 837 & 85 & 183 & 333 & 976 & 0 & 25 & $0 \%$ & $3 \%$ & 0 & 9 \\
\hline ALL & 3346 & 5246 & 75 & 366 & 388 & 920 & 84 & 197 & 335 & 1001 & 51 & 257 & $15 \%$ & $26 \%$ & 13 & 84 \\
\hline ALL-H2REDIS & 3342 & 5257 & 97 & 325 & 381 & 865 & 82 & 186 & 335 & 1009 & 65 & 228 & $20 \%$ & $23 \%$ & 21 & 80 \\
\hline
\end{tabular}

increases the size of a few ones. The diurnal distribution of $\mathrm{H}_{2}$ and the congestion issue is illustrated in the hourly energy balance of $\mathrm{H}_{2}$ of the so-called, in this paper, central Norwegian hub in Figure 13.

The contribution of $\mathrm{H}_{2}$ storage to the total generation of $\mathrm{H}_{2}$ is so important that it accounts for overall $50 \%$ of the $\mathrm{H}_{2}$ generated with electrolysers in most of the scenarios (Figure 14). The share of storage usage decreases when $\mathrm{H}_{2}$ is forced to be generated offshore because the solar pattern has a lower influence on $\mathrm{H}_{2}$ generation in these scenarios. The large share of the use of $\mathrm{H}_{2}$ storage is remarkable compared to the share of electricity storage, which plays a limited role in most of the scenarios (5\% in scenario BASE, with around $87 \%$ of it provided by flexible electric vehicles). The contribution of heat storage is also relatively large and similar in all the scenarios (around 14\% on average by 2045), although lower compared to $\mathrm{H}_{2}$ storage. In the scenarios where offshore caverns are allowed, more than
$50 \%$ of the $\mathrm{H}_{2}$ storage generation takes place in them.

The alternative solution of having a more constant generation of $\mathrm{H}_{2}$ in the electrolysers that would require a more stable electricity input that could come from the combination of wind generation and electricity batteries, i.e. a solution with less need for $\mathrm{H}_{2}$ storage, is not found as the least-cost solution by the model. The reason for this result is the combination of technology data assumptions used. Batteries are much more expensive (Table 1) and have a lower lifetime than $\mathrm{H}_{2}$ storage, and solar PV becomes significantly cheaper towards 2050. As shown previously, decreasing the cost reduction of the electrolysers towards 2050 in scenario ELYZERCOST does not lead to significant changes compared to the BASE scenario.

\subsection{Offshore hubs are mainly used to deliver electricity to shore}

Except for the scenarios where offshore $\mathrm{H}_{2}$ generation is forced, the total generation and capacity from hub-connected 

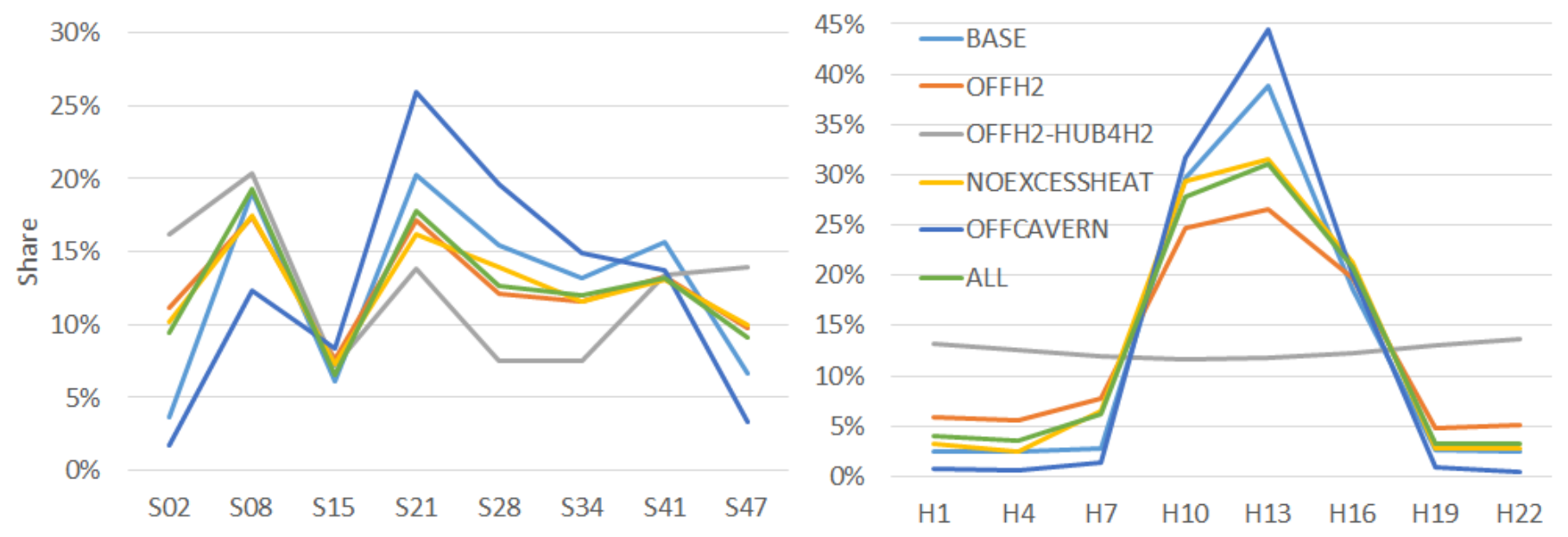

Figure 7: Share of total electricity demand for $\mathrm{H}_{2}$ generation in the hubs per modelled season (week) (left figure) and hour (right figure) for selected scenarios in 2045 .

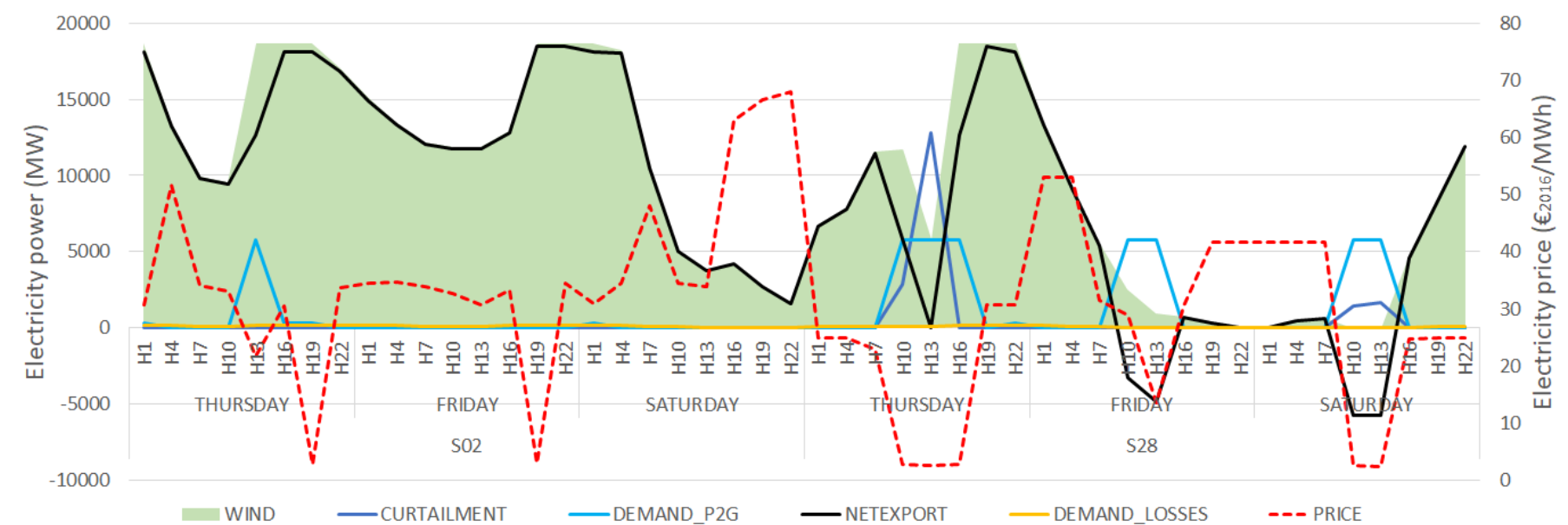

Figure 8: Electricity balance at the so-called in this paper central Norwegian hub in 2045 in scenario BASE for selected modelled seasons (weeks). DEMAND_P2G corresponds to the electrolyser consumption.

wind farms is rather similar (Figure 6 and Table 4), being the main purpose of this electricity generation to be sent and consumed onshore, and not to generate $\mathrm{H}_{2}$ offshore.

In the scenarios where $\mathrm{H}_{2}$ is not forced to be generated offshore, the installed interconnection capacity of each hub is, generally, at least of the size of the installed wind capacity, whereas the electrolyser one is generally lower than the wind capacity in the scenarios (Figure 15). This implies that the hubs are designed to be able to export their maximum wind generation, and not with an electrolyser capacity that would allow them to consume the maximum wind generation in each hub. Even though the power curtailment can be as high as the maximum electricity generation in the hub, it is preferred to curtail this excess energy than investing in higher electrolyser capacity to be able to absorb it. Overall, and as long as the hubs are allowed to be electrically connected to shore, the higher the importance of offshore $\mathrm{H}_{2}$ generation, the higher the ratio of electrolyser capacity and wind capacity (Figure 15). In the scenario where all wind generation in the hubs can only be used to generate $\mathrm{H}_{2}$ (scenario OFFH2-HUB4H2), the ratio of electrolyser capacity and wind capacity is on average 0.92 , which suggests that the electrolyzer capacity of each hub is roughly in line with the installed wind capacity of the hub.

Most of the electricity demand consumed to generate $\mathrm{H}_{2}$ in the hubs, which follows the solar PV pattern in most of the scenarios, is coming from the electricity wind generation of the same hub (Figure 16). The graph also shows that, in general, the lower the electrolyser demand in each hub, the higher the share of electricity that is generated by wind in the same offshore region, which is an intuitive result.

\subsection{Forcing $\mathrm{H}_{2}$ generation offshore leads to higher costs and higher emissions}

The restriction of requiring all $\mathrm{H}_{2}$ generation to take place offshore leads to higher costs (Figure 17). The additional cost of this restriction increases towards 2050 , following the increasing 

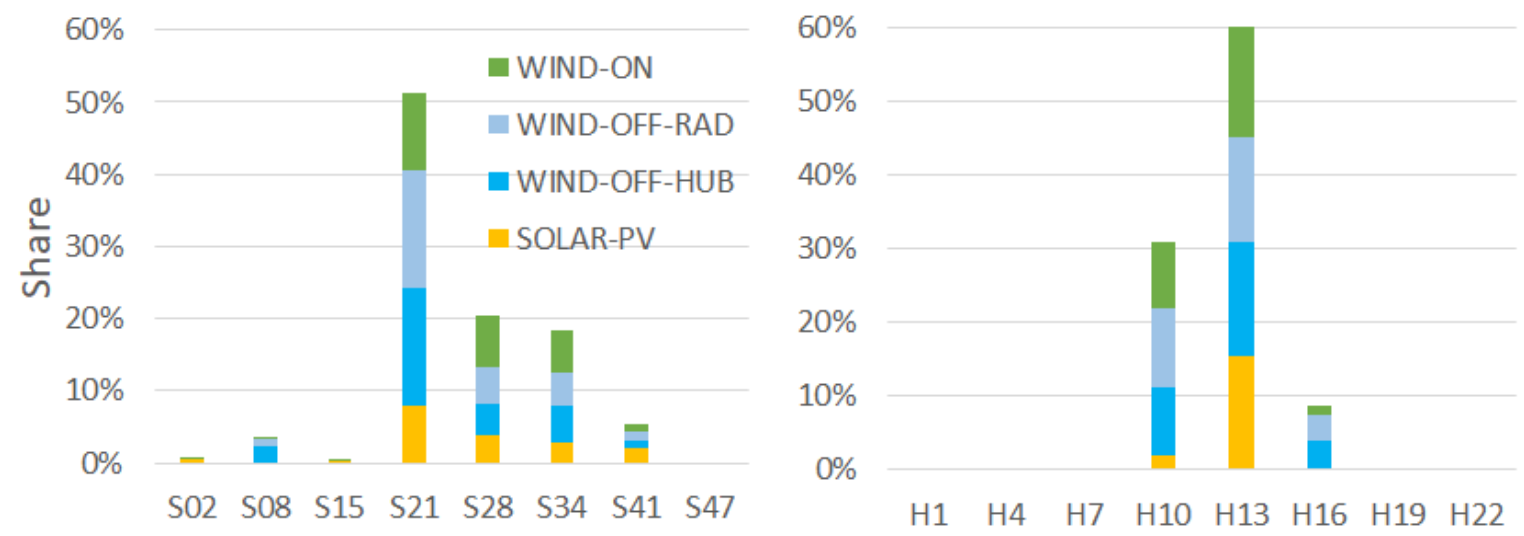

Figure 9: Energy curtailment share in 2045 in scenario BASE per modelled season (week) (left figure) and hour (right figure).

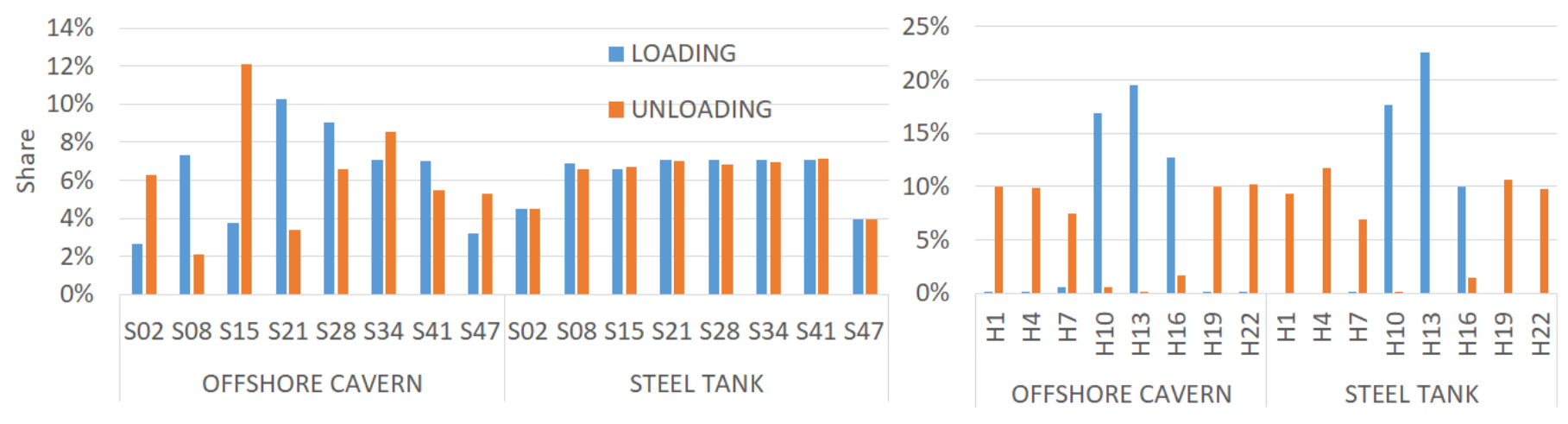

Figure 10: Share of $\mathrm{H}_{2}$ storage use per storage type in each season (left figure) and hour (right figure) in 2045 in scenario ALL.

need for $\mathrm{H}_{2}$ in the system. By 2045 and compared to BASE, the additional cost of the system in scenarios OFFH2 and OFFH2HUB4H2 is 9.4 and 27.8 b $€_{2016}$ /year, respectively (4.4\% and $12.8 \%$ of the costs by 2045 in scenario BASE). This suggests that forcing $\mathrm{H}_{2}$ generation offshore has around 3 times higher impact by 2045 when the electrical connection to shore is not allowed. The cost increase of forcing $\mathrm{H}_{2}$ generation to take place offshore is mainly related to the larger costs of hub-connected wind farms compared to solar PV.

In all the scenarios the $\mathrm{CO}_{2}$ emissions decrease greatly towards 2050, being almost negligible by 2045, which is a consequence of the high $\mathrm{CO}_{2}$ price assumed. Forcing $\mathrm{H}_{2}$ generation to take place offshore leads to higher emissions in the studied period though. Compared to the BASE scenario, in the studied 30 year period from 2020-2050 the additional $\mathrm{CO}_{2}$ emissions in scenarios OFFH2 and OFFH2-HUB4H2 are 77 Mtons and 255 Mtons, respectively.

\subsection{Redistribution moves $\mathrm{H}_{2}$ demand for transport to France}

Allowing for the redistribution of the regional $\mathrm{H}_{2}$ demand for the transport sector tends to allocate most of this demand to France (Table 5). The reason for this is that, as explained previously, the combination of solar PV pattern, electrolyser and $\mathrm{H}_{2}$ storage is found to be the most cost-effective way of dealing with the $\mathrm{H}_{2}$ demand, and France has good solar resources. Part of the $\mathrm{H}_{2}$ demand for the transport sector is indeed allocated to the hubs, but the overall role of offshore $\mathrm{H}_{2}$ generation towards 2050 is reduced when the $\mathrm{H}_{2}$ demand for transport is allowed to be redistributed (Table 4 ).

\section{Discussion}

Our optimisation results suggest that offshore $\mathrm{H}_{2}$ generation should play a limited role in the future integrated energy system and that offshore wind should mostly be used to deliver its electricity generation onshore. This is because the generation of $\mathrm{H}_{2}$ follows the solar PV pattern and combined with $\mathrm{H}_{2}$ storage is found cost-effective to satisfy the $\mathrm{H}_{2}$ demand. The costs related to the generation of electricity required to generate $\mathrm{H}_{2}$ with the electrolysers play a key role, larger than, for instance, the capital expenditure of the electrolysers. If the capital expenditure of the electrolysers had been more decisive, offshore $\mathrm{H}_{2}$ generation would have likely become more important because of the higher capacity factor of offshore wind with respect to solar PV. These results are diverging from Franco et al., 2021, who found that inland generation of $\mathrm{H}_{2}$ would only be promising for wind farms close to shore and that offshore $\mathrm{H}_{2}$ generation transported via $\mathrm{H}_{2}$ pipeline was generally preferred. The cost of $\mathrm{H}_{2}$ piping is likely to be cheaper than electric sea cables when going far offshore (see Table 2), but just focusing on costs and neglecting the value creation aspect can lead to sub-optimal solutions for 


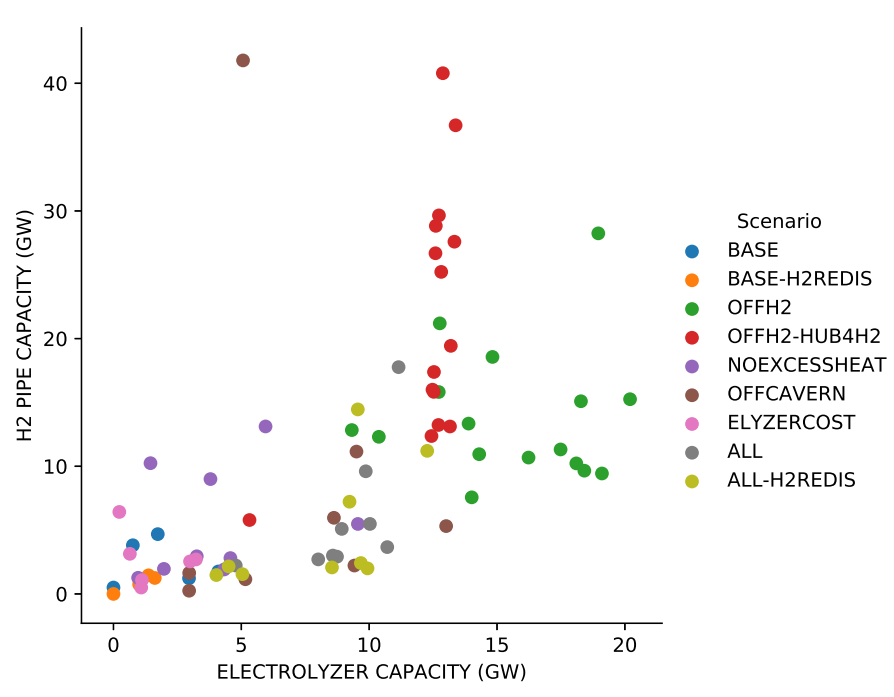

Figure 11: Installed electrolyser capacity versus aggregated $\mathrm{H}_{2}$ pipe capacity in each hub 2045 per scenario. Aggregated $\mathrm{H}_{2}$ pipe capacity is calculated summing the capacity of all the pipes connected to each hub. Each dot corresponds to one hub. Numbers correspond to thermal power of $\mathrm{H}_{2}$.

the overall integrated energy system. Therefore, using a holistic approach where the synergies and time-dependent value of the technologies in different regions is captured, rather than using for instance techno-economic feasibility analysis based on levelised cost of $\mathrm{H}_{2}$, seems to be key to derive meaningful conclusions on how offshore wind energy should be used and the role of the different players of the energy system.

There are several uncertainties related to our results. First, we expect that actual cost associated with offshore $\mathrm{H}_{2}$ generation are likely to be higher than assumed in this paper, as building and maintaining electrolysers offshore will have additional costs as compared to onshore - which we could not consider in the modelling due to lack of reliable data. Hence, we assess that our resulting offshore $\mathrm{H}_{2}$ shares may even be optimistic. Second, we did not include the option to repurpose existing infrastructure for offshore $\mathrm{H}_{2}$ transportation. This could increase the value of offshore $\mathrm{H}_{2}$ generation, since adapting existing infrastructure is likely to have lower costs than building new pipes. Nevertheless, this argument is also valid for onshore gas infrastructure. Third, the space requirement for offshore electrolyser capacity could also be an issue. In the scenarios, the installed electricity capacity of electrolysers in the hubs varies from 6$357 \mathrm{GW}$. Assuming that each electrolyser requires $8 \mathrm{~m}^{2} / \mathrm{MWe}$ (Danish Energy Agency, 2021) leads to requiring a surface of $0.05-2.86 \mathrm{~km}^{2}$ just for electrolyser equipment. This size is $0.1-$ 6.2 times the size of the energy island that Denmark intends to build. This may become both a cost and a logistical issue. Also, the increased space requirement might be in competition with other sectors, like fishing. Other important aspects like the availability of hydro resources onshore have not been included in the modelling. Assuming onshore water scarcity could potentially require using sea water also for onshore electrolysers
Table 5: $\mathrm{H}_{2}$ demand for the transport sector per year, location, and selected scenario (TWh). The $\mathrm{H}_{2}$ demand in the hubs is aggregated as "Offshore hubs".

\begin{tabular}{|c|c|c|c|c|c|}
\hline Year & Location & BASE & BASE-H2REDIS & ALL & ALL-H2REDIS \\
\hline \multirow{4}{*}{$\mathbf{4 0 3 5}$} & Belgium & 9 & 0 & 9 & 0 \\
\cline { 2 - 6 } & Denmark & 3 & 4 & 3 & 0 \\
\cline { 2 - 6 } & Finland & 8 & 0 & 8 & 0 \\
\cline { 2 - 6 } & France & 69 & 189 & 69 & 239 \\
\cline { 2 - 6 } & Germany & 78 & 0 & 78 & 0 \\
\cline { 2 - 6 } & Netherlands & 13 & 0 & 13 & 0 \\
\cline { 2 - 6 } & Norway & 3 & 7 & 3 & 0 \\
\cline { 2 - 6 } & Poland & 20 & 58 & 20 & 25 \\
\cline { 2 - 6 } & Sweden & 20 & 1 & 20 & 0 \\
\cline { 2 - 6 } & United Kingdom & 41 & 5 & 41 & 0 \\
\hline Offshore hubs & 0 & 0 & 0 & 0 \\
\cline { 2 - 6 } & Belgium & 23 & 0 & 23 & 0 \\
\cline { 2 - 6 } & Denmark & 9 & 3 & 9 & 0 \\
\cline { 2 - 6 } & Finland & 22 & 0 & 22 & 0 \\
\cline { 2 - 6 } & France & 183 & 443 & 183 & 629 \\
\cline { 2 - 6 } & Germany & 208 & 34 & 208 & 5 \\
\cline { 2 - 6 } & Netherlands & 35 & 11 & 35 & 0 \\
\cline { 2 - 6 } & Norway & 9 & 4 & 9 & 0 \\
\cline { 2 - 6 } & Poland & 53 & 67 & 53 & 0 \\
\cline { 2 - 6 } & Sweden & 52 & 0 & 52 & 09 \\
\cline { 2 - 6 } & United Kingdom & 109 & 134 & 109 & 0 \\
\cline { 2 - 6 } & Offshore hubs & 0 & 9 & & 0 \\
\hline
\end{tabular}

(when close to shore), and lead to increased cost due to desalination and water transport. This would improve the case for offshore $\mathrm{H}_{2}$ generation. Other modelling assumptions like assuming perfect competition, economic rationality, and linear power and gas flows, as well as data assumptions like VRE technology development could also have influenced the results. Behavioural and social aspects, which can considerably influence the acceptability of e.g. transmission reinforcement, could be accounted in future research.

Offshore $\mathrm{H}_{2}$ generation has recently come into strong focus in the European energy debate, with many proponents of the option. While our paper finds that offshore $\mathrm{H}_{2}$ generation would lead to increased socio-economic costs towards 2050, there are many possible reasons for why offshore $\mathrm{H}_{2}$ generation could still be a beneficial option to pursue. Discussing them all in detail would go beyond the scope of this paper, but we would like to emphasise a few factors that may need to be weighed against each other for an informed decision. First, by placing $\mathrm{H}_{2}$ generation offshore, substantial reinforcement of the onshore electricity grid could be avoided, which can be hindered and slowed down by social acceptance issues (Battaglini et al., 2012). Modelling the required onshore electricity grid reinforcement with higher accuracy is not an easy task without increasing the spatial resolution of the electricity network, which can make the problem intractable. Second, market arrangements for offshore electricity generation, tariff and price structures, cross-border interconnection and allocation of congestion rents all have an important role in setting investment incentives, and may make offshore $\mathrm{H}_{2}$ generation attractive for some stakeholders. Third, there may be other value elements and business options, both onshore and offshore, that we simply cannot capture in energy system modelling and that are likely to play a large role in decision making. These could e.g. span from new offshore fuel demand options, over logistical and planning constraints, to spa- 


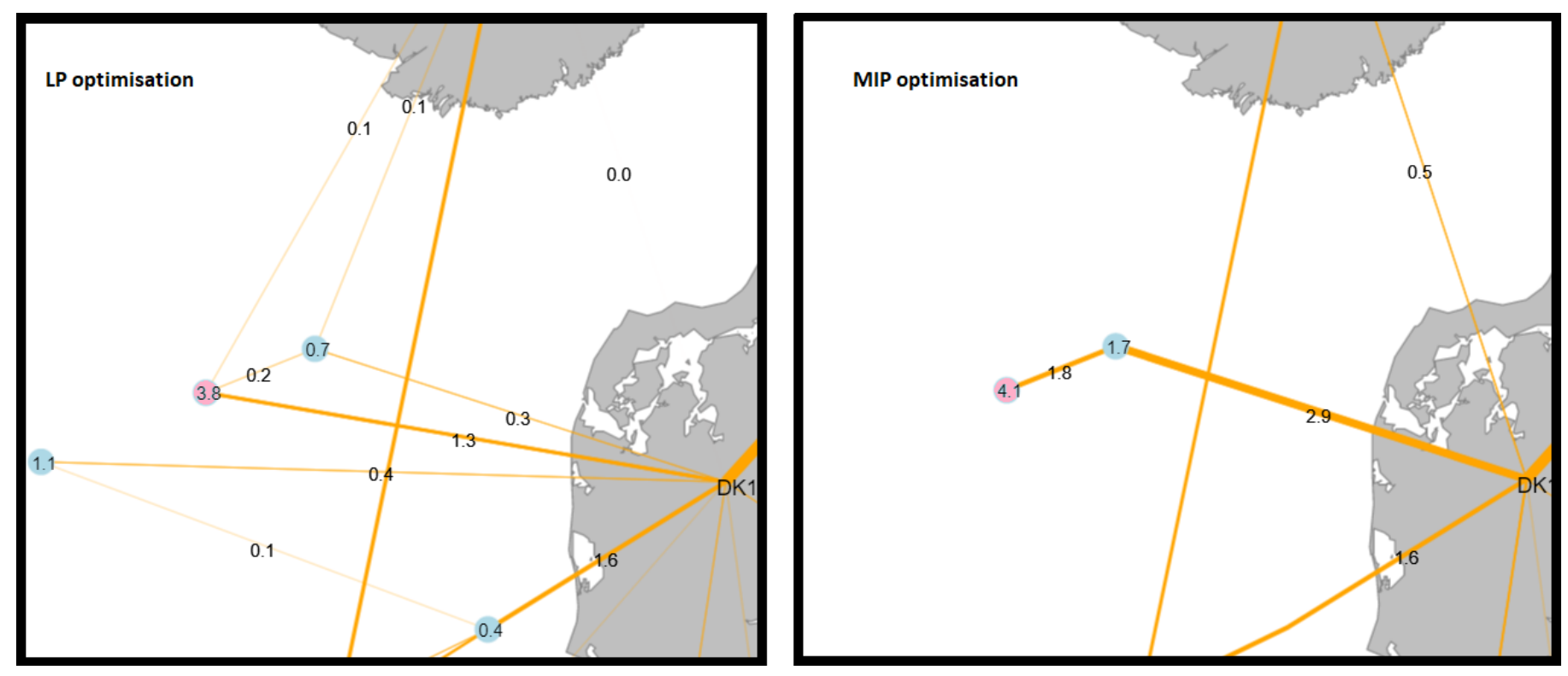

Figure 12: Influence of linear programming (LP) (left figure) and mixed integer programming (MIP) (right figure) on offshore $\mathrm{H}_{2}$ grid in 2045 in scenario BASE. Hubs correspond to the blue dots (pink for the so-called in this paper central Norwegian hub) and $\mathrm{H}_{2}$ pipes to the yellow lines. Only the hubs with electrolyser capacity investments are shown. The electrolyzer capacity in the hubs is the number inside the blue dots, and the number on top of the yellow lines is the $\mathrm{H}_{2}$ pipe capacity. All numbers are in GW and have been rounded to the first decimal.

tial and justice considerations.

\section{Conclusions and policy implications}

By performing energy system optimisation from a socioeconomic point of view, this paper has investigated the role of offshore $\mathrm{H}_{2}$ generation in the energy system towards 2050 . We have used the North Sea region as a showcase, but the general insights are also valid for other regions with large wind and solar PV potentials.

In our scenarios, the generation of $\mathrm{H}_{2}$ in the electrolysers following the solar PV pattern, combined with the extensive use of $\mathrm{H}_{2}$ storage, is the most cost-effective solution to cover the expected increasing $\mathrm{H}_{2}$ demand towards 2050. The costs associated to the generation of electricity to feed the electrolysers play a key role, larger than for instance the capital expenditure of the electrolysers. As a result, most $\mathrm{H}_{2}$ generation towards 2050 takes place onshore, and hence, offshore $\mathrm{H}_{2}$ generation has a limited role.

From a socio-economic perspective, we find that offshore wind generation, which increases considerably towards 2050, has higher value when sent to shore. Even when offshore hubs are electrically connected to shore, the (limited) offshore $\mathrm{H}_{2}$ generation follows a solar PV generation pattern.

Forcing $\mathrm{H}_{2}$ generation to take place offshore would lead to a considerable socio-economic total energy system cost increase (9-28 b $€_{2016} /$ year by 2045), and to slightly higher emissions (77-255 Mtons from 2020 to 2050). Restricting the use of the excess heat of onshore electrolysers in district heating networks and/or having the possibility to use offshore caverns as $\mathrm{H}_{2}$ storage can increase the role of offshore $\mathrm{H}_{2}$ generation significantly.
Overall, we conclude that offshore $\mathrm{H}_{2}$ generation, if it was to be pursued substantially in the future, must be legitimised by other reasons than socio-economic benefits. These could include technical, logistical, planning, environmental or other reasons. In any case, stronger political efforts to enable and promote the direct integration of offshore wind energy via electrical connection to the onshore system seems to us as a noregret option for the transition of the European energy system towards sustainability.

We see the following policy implications arise from our analysis:

- An economically no-regret option would be to place a large amount of $\mathrm{H}_{2}$ generation onshore - it will require substantial political effort to remove barriers and incentivise substantial investment into $\mathrm{H}_{2}$ generation facilities.

- Offshore $\mathrm{H}_{2}$ generation is most likely not the most attractive solution from socio-economic system cost considerations, so it is debatable as major political argument for incentivising offshore $\mathrm{H}_{2}$ generation - but arguments around other benefits may prevail.

- If policy prioritises other (non-economic) factors and decides to placing some $\mathrm{H}_{2}$ offshore, it should still always be connected to the electricity grid, so that its full value can be captured in the integrated energy system.

- The full integration of $\mathrm{H}_{2}$ generation - be it onshore or offshore - into the energy system also implies that it can be complex to determine where exactly the electricity that is being used for $\mathrm{H}_{2}$ generation was generated. Here, a clear 


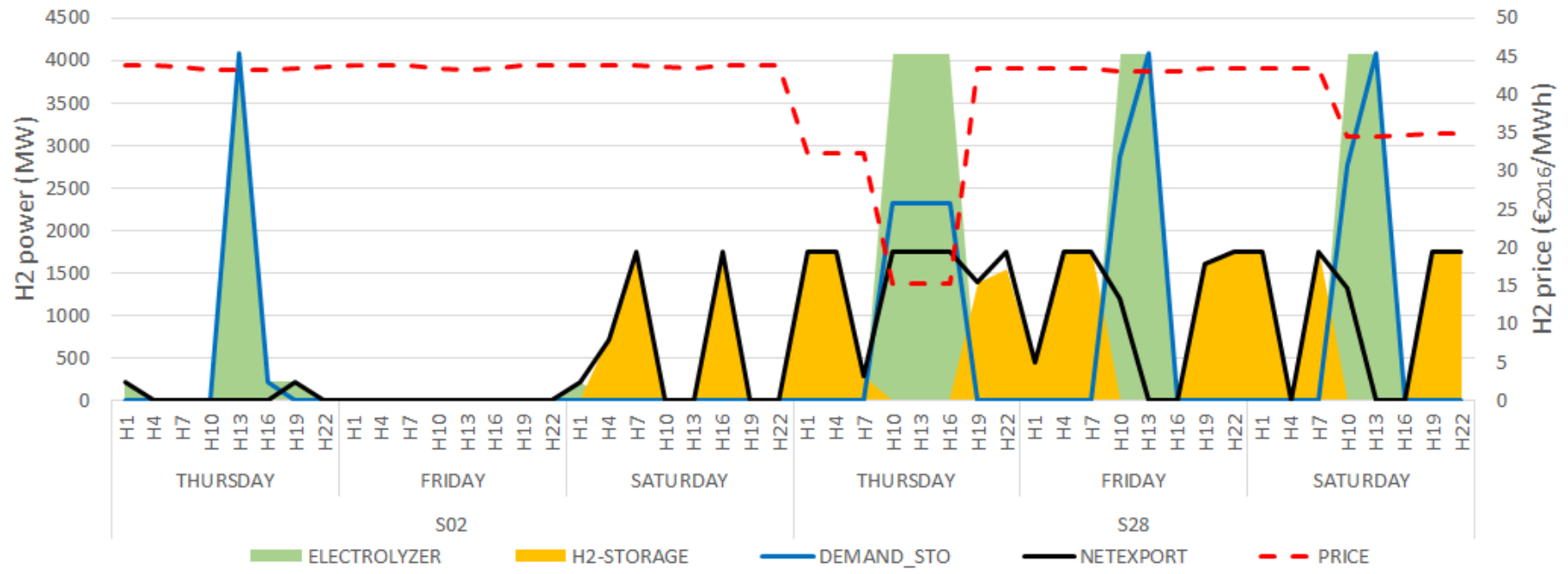

Figure 13: $\mathrm{H}_{2}$ balance balance at the so-called in this paper central Norwegian hub in 2045 in scenario BASE for selected modelled seasons. DEMAND_STO corresponds to the loading of the $\mathrm{H}_{2}$ storage.

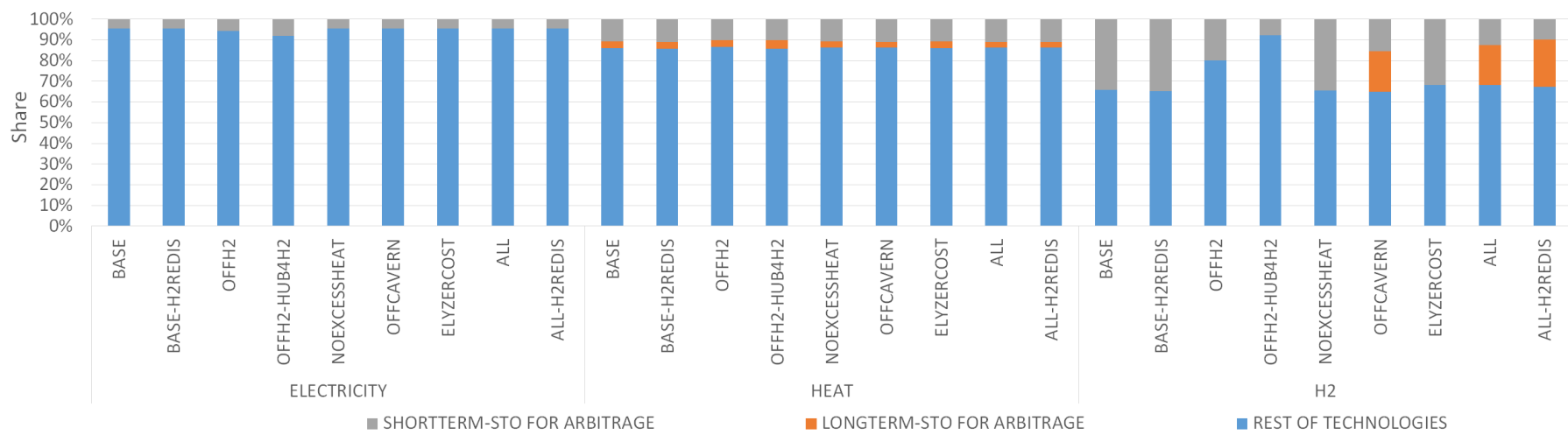

Figure 14: Share of storage use for price arbitrage in total generation per scenario and commodity in 2045. Hydro reservoir without pumping is not considered storage for price arbitrage, since it can only discharge energy.

and transparent definition of 'green hydrogen' is required, alongside a regulatory implementation that is broad, flexible and reliable enough to allow the capturing of the additional environmental attributes when e.g. offshore wind or solar PV is used as input.

- The future energy system with a large generation of $\mathrm{H}_{2}$ will be depending even more on international policy collaboration. Action will be needed on the expansion of interconnectors across the whole of Europe, alignment of market rules to enable equal interaction across all energy vectors, as well as the reliable and timely expansion of joint offshore infrastructure.

$\mathrm{H}_{2}$ is likely to play a large role in the future European energy system. We are at a crossroads today to set the path for how the future system will look like. Our results are a contribution to the discussion about where to place $\mathrm{H}_{2}$ generation and we found indications that it would be more cost-effective to place it onshore - but certainly this discussion is not finally solved and further analysis, especially on the non-economic issues, will certainly shed even more light on the debate.

\section{Acknowledgments}

This article is a part of NSON-DK project funded by the Danish Energy Agency, EUDP (grant 64018-0032; previously ForskEL), the Flex4Res project funded by Nordic Energy Research (grant 76084), and the SuperP2G project financed by the European Union's Horizon 2020 research and innovation programme (grant number 775970). Matti Koivisto acknowledges support from the PSfuture project (La Cour Fellowship, DTU Wind Energy).

\section{References}

A. Babarit, J.-C. Gilloteaux, G. Clodic, M. Duchet, A. Simoneau, and M. F. Platzer. Techno-economic feasibility of fleets of far offshore hydrogenproducing wind energy converters. International Journal of Hydrogen Energy, 43(15):7266-7289, 2018. ISSN 0360-3199. doi: https://doi.org/10. 1016/j.ijhydene.2018.02.144. 


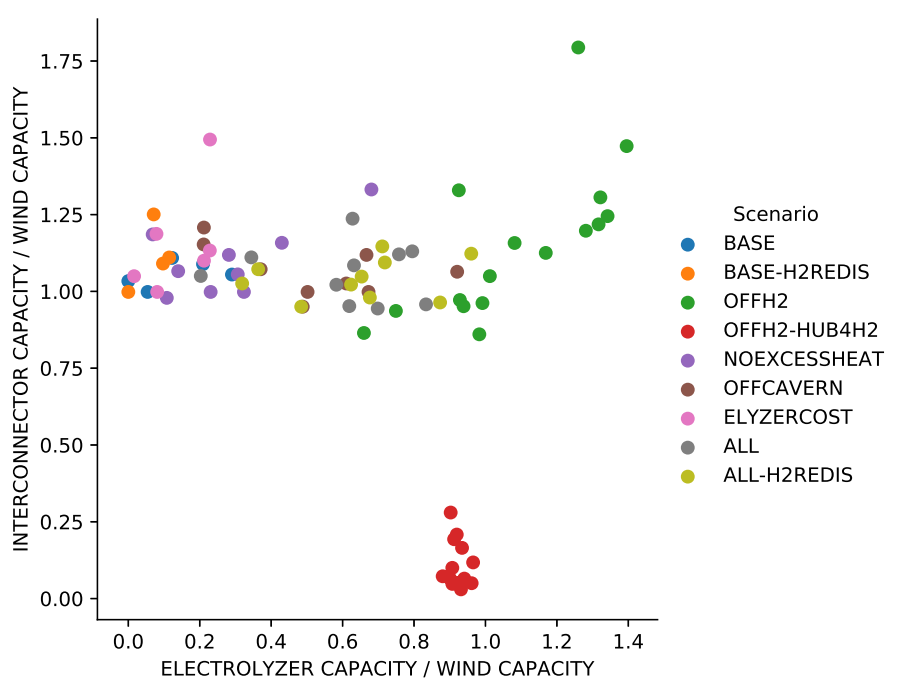

Figure 15: Ratio of aggregated electricity interconnector capacity and installed wind capacity in each hub versus ratio of installed electrolyzer electricity input capacity and wind capacity in each hub per scenario in 2045. Each dot corresponds to a hub. The aggregated electricity interconnector capacity of each hub is calculated summing all the interconnectors connected to that hub.

Balmorel community. Balmorel code, 2021a. URL https://github.com/ balmorelcommunity/Balmorel.

Balmorel community. Balmorel data, 2021b. URL https:/github.com/ balmorelcommunity/Balmorel_data.

A. Battaglini, N. Komendantova, P. Brtnik, and A. Patt. Perception of barriers for expansion of electricity grids in the european union. Energy Policy, 47: 254 - 259, 2012. ISSN 0301-4215. doi: https://doi.org/10.1016/j.enpol. 2012.04.065.

R. Bramstoft, A. Alonso, I. Jensen, H. Ravn, and M. Munster. Modelling of Renewable Gas And Fuels In Future Integrated Energy Systems. Applied Energy, 268, 2020. ISSN 0306-2619. doi: 10.1016/j.apenergy.2020.114869. URL https://doi.org/10.1016/j.apenergy.2020.114869.

T. Brown, D. Schlachtberger, A. Kies, S. Schramm, and M. Greiner. Synergies of sector coupling and transmission reinforcement in a cost-optimised, highly renewable european energy system. Energy, 160:720-739, 2018. doi: https://doi.org/10.1016/j.energy.2018.06.222.

Danish Energy Agency. Technology Catalogues, 2021. URL https://ens.dk/en/ our-services/projections-and-models/technology-data.

V. N. Dinh, P. Leahy, E. McKeogh, J. Murphy, and V. Cummins. Development of a viability assessment model for hydrogen production from dedicated offshore wind farms. International Journal of Hydrogen Energy, 2020. ISSN 0360-3199. doi: https://doi.org/10.1016/j.ijhydene.2020.04.232.

DW. Denmark to construct artificial island as a wind energy hub, 2021. URL https://www.dw.com/en/denmark-to-construct-artificial-island-as-a-windenergy-hub/a-56458179\#: :text=Denmark\%20approved\%20plans\% 20on $\% 20$ Thursday, aviation $\% 2 \mathrm{C} \% 20$ industry $\% 20$ and $\% 20$ heavy $\%$ 20transport.

EA Energy Analysis. Offshore wind and infrastructure, 2020. URL https://www.ea-energianalyse.dk/en/publications/offshore-wind-andinfrastructure/.

EDMOnet-Bathymetry. EMODnet DTM, 2021. URL https://portal.emodnetbathymetry.eu/.

O. B. Egelund. Wind energy and local acceptance; how to get beyond the nimby effect. European Energy and Environmental Law Review, pages 239251, 2010. ISSN 0966-1646. URL http://www.kluwerlawonline.com/api/ Product/RenderPDF?file=Journals2010017.pdf.

European Commission. A Clean Planet for all A European long-term strategic vision for a prosperous, modern, competitive and climate neutral econ-

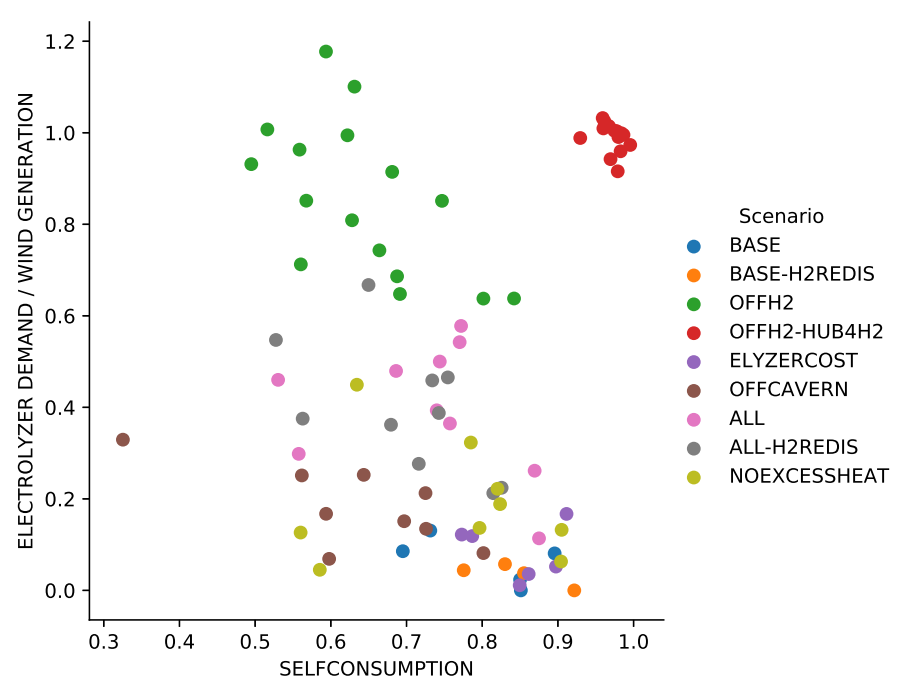

Figure 16: Ratio of electricity demand in the electrolyser in the hub and the wind generation in the same hub versus selfconsumption in each hub per scenario in 2045. Selfconsumption is defined as the ratio between the electricity demand in the electrolyser that is covered with wind generation in the same hub, and the total electricity demand in the electrolysers of that hub. Data shown only for hubs with electrolyser demand in 2045. Each dot corresponds to one hub.

omy, 2018. URL https://ec.europa.eu/clima/sites/clima/files/docs/pages/ com_2018_733_analysis_in_support_en_0.pdf.

Flex4RES project. Flexible Nordic Energy Systems summary report, 2019. URL https://www.nordicenergy.org/wp-content/uploads/2019/07/ Flex4RES_final_summary_report_aug2019.pdf.

B. A. Franco, P. Baptista, R. C. Neto, and S. Ganilha. Assessment of offloading pathways for wind-powered offshore hydrogen production: Energy and economic analysis. Applied Energy, 286:116553, 2021. ISSN 0306-2619. doi: https://doi.org/10.1016/j.apenergy.2021.116553.

J. Gea-Bermúdez, L. L. Pade, M. J. Koivisto, and H. Ravn. Optimal generation and transmission development of the north sea region: Impact of grid architecture and planning horizon. Energy, 191:116512, 2020. ISSN 0360-5442. doi: https://doi.org/10.1016/j.energy.2019.116512.

J. Gea-Bermúdez, K. Das, M. J. Koivisto, and H. koduvere. Day-ahead Market Modelling of Large-scale Highly-renewable Multi-energy Systems: Analysis of the North Sea Region Towards 2050. Energies, 14, 2021a. doi: https://doi.org/10.3390/en14010088.

J. Gea-Bermúdez, I. G. Jensen, M. Münster, M. Koivisto, J. G. Kirkerud, Y. kuang Chen, and H. Ravn. The role of sector coupling in the green transition: A least-cost energy system development in northern-central europe towards 2050. Applied Energy, 289:116685, 2021b. ISSN 0306-2619. doi: https://doi.org/10.1016/j.apenergy.2021.116685.

P. A. Gunkel, C. Bergaentzlé, I. Græsted Jensen, and F. Scheller. From passive to active: Flexibility from electric vehicles in the context of transmission system development. Applied Energy, 277:115526, 2020a. ISSN 03062619. doi: https://doi.org/10.1016/j.apenergy.2020.115526.

P. A. Gunkel, H. Koduvere, J. G. Kirkerud, F. J. Fausto, and H. Ravn. Modelling transmission systems in energy system analysis: A comparative study. Journal of Environmental Management, 262:110289, 2020b. ISSN 0301-4797. doi: https://doi.org/10.1016/j.jenvman.2020.110289.

B. Helgeson and J. Peter. The role of electricity in decarbonizing european road transport - development and assessment of an integrated multi-sectoral model. Applied Energy, 262:114365, 2020. ISSN 0306-2619. doi: https: //doi.org/10.1016/j.apenergy.2019.114365.

H.-M. Henning and A. Palzer. A comprehensive model for the german electricity and heat sector in a future energy system with a dominant contribution from renewable energy technologies-part i: Methodology. Renewable and 


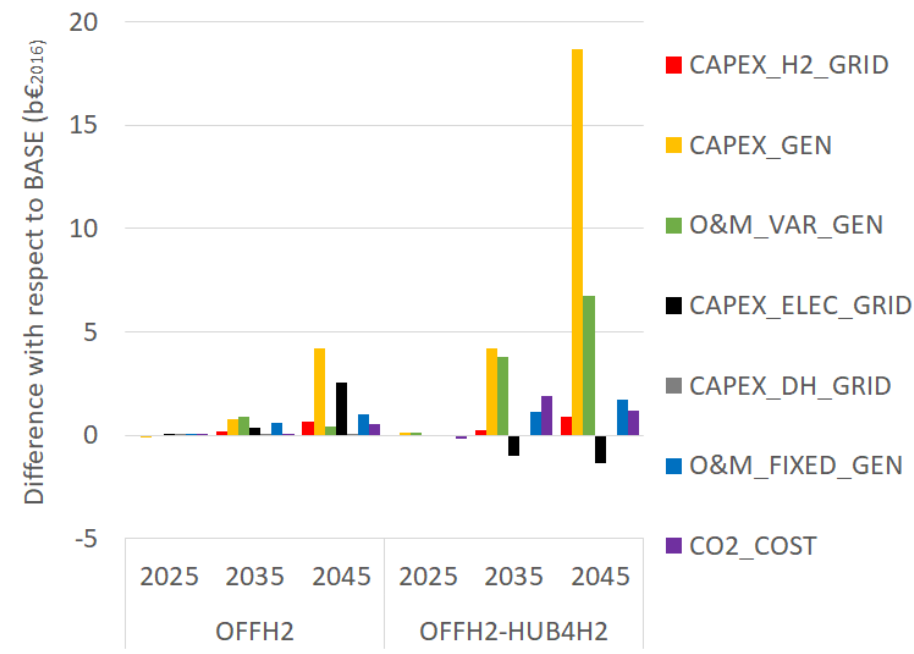

Figure 17: Difference between energy system costs of selected scenarios and scenario BASE per year. GEN stands for generation and storage, $\mathrm{DH}$ for district heating, VAR for variable, and ELEC for electricity.

Sustainable Energy Reviews, 30:1003 - 1018, 2014. ISSN 1364-0321. doi: https://doi.org/10.1016/j.rser.2013.09.012.

P. Hou, P. Enevoldsen, J. Eichman, W. Hu, M. Z. Jacobson, and Z. Chen. Optimizing investments in coupled offshore wind -electrolytic hydrogen storage systems in denmark. Journal of Power Sources, 359:186-197, 2017. ISSN 0378-7753. doi: https://doi.org/10.1016/j.jpowsour.2017.05.048.

IEA. IEA G20 Hydrogen report: assumptions, 2019.

I. G. Jensen, F. Wiese, R. Bramstoft, and M. Münster. Potential role of renewable gas in the transition of electricity and district heating systems. Energy Strategy Reviews, 27(November 2019):100446, 2020. ISSN 2211467X. doi: 10.1016/j.esr.2019.100446. URL https://doi.org/10.1016/j.esr.2019.100446.

M. Koivisto and J. Gea-Bermúdez. NSON-DK energy system scenarios - Edition 2. DTU Wind Energy, Denmark, 2018. https://orbit.dtu.dk/en/publications/nsondk-energy-system-scenarios-edition-2(a12307fd-b045-4d90-a745-38bca211b861).html.

M. Koivisto, K. Das, F. Guo, P. Sørensen, E. Nuño, N. Cutululis, and P. Maule. Using time series simulation tools for assessing the effects of variable renewable energy generation on power and energy systems. Wiley Interdisciplinary Reviews: Energy and Environment, 8(3):e329, 2019a. doi: 10.1002/wene.329.

M. Koivisto, J. Gea-Bermúdez, and P. Sørensen. North sea offshore grid development: Combined optimization of grid and generation investments towards 2050. IET Renewable Power Generation, November 2019b. ISSN 1752-1416. doi: 10.1049/iet-rpg.2019.0693.

I. Konstantelos, D. Pudjianto, G. Strbac, J. De Decker, P. Joseph, A. Flament, P. Kreutzkamp, F. Genoese, L. Rehfeldt, A.-K. Wallasch, G. Gerdes, M. Jafar, Y. Yang, N. Tidemand, J. Jansen, F. Nieuwenhout, A. van der Welle, and K. Veum. Integrated north sea grids: The costs, the benefits and their distribution between countries. Energy Policy, 101:28 - 41, 2017. ISSN 0301-4215. doi: https://doi.org/10.1016/j.enpol.2016.11.024.

Lazard. Lazard's levelized cost of storage analysis 3.0, 2017. URL https:// www.lazard.com/perspective/levelized-cost-of-storage-2017/.

M. S. Lester, R. Bramstoft, and M. Münster. Analysis on Electrofuels in Future Energy Systems: A 2050 Case Study. Energy, 199:117408, 2020. ISSN 03605442. doi: 10.1016/j.energy.2020.117408. URL https://doi.org/10. 1016/j.energy.2020.117408.

S. McDonagh, S. Ahmed, C. Desmond, and J. D. Murphy. Hydrogen from offshore wind: Investor perspective on the profitability of a hybrid system including for curtailment. Applied Energy, 265:114732, 2020. ISSN 03062619. doi: https://doi.org/10.1016/j.apenergy.2020.114732.

M. Münster, P. E. Morthorst, H. V. Larsen, L. Bregnbæk, J. Werling, H. H. Lindboe, and H. Ravn. The role of district heating in the future danish energy system. Energy, 48(1):47 - 55, 2012. ISSN 0360-5442. doi: https://doi.org/ 10.1016/j.energy.2012.06.011. 6th Dubrovnik Conference on Sustainable Development of Energy Water and Environmental Systems, SDEWES 2011.

N. B. Negra, J. Todorovic, and T. Ackermann. Loss evaluation of hvac and hvdc transmission solutions for large offshore wind farms. Electric Power Systems Research, 76(11):916 - 927, 2006. ISSN 0378-7796. doi: https: //doi.org/10.1016/j.epsr.2005.11.004.

Nordic Energy Research and International Energy Agency. Nordic Energy Technology Perspectives 2016 report, 2016. URL http://www.nordicenergy. org/project/nordic-energytechnology-perspectives/.

E. Nuño, P. Maule, A. Hahmann, N. Cutululis, P. Sørensen, and I. Karagali. Simulation of transcontinental wind and solar PV generation time series. 118:425-436, 2018.

Philip Swisher. Modelling of Political and Technological Innovation on Northern Europe's Energy System Towards 2050, 2020. URL https://findit.dtu. dk/en/catalog/2595776848.

K. Poncelet, E. Delarue, and W. D'haeseleer. Unit commitment constraints in long-term planning models: Relevance, pitfalls and the role of assumptions on flexibility. Applied Energy, 258:113843, 2020. ISSN 0306-2619. doi: https://doi.org/10.1016/j.apenergy.2019.113843.

M. Rehfeldt, T. Fleiter, and F. Toro. A bottom-up estimation of the heating and cooling demand in european industry. Energy Efficiency, 11:1057-1082, 2018. doi: https://doi.org/10.1007/s12053-017-9571-y.

P. Ruiz, W. Nijs, D. Tarvydas, A. Sgobbi, A. Zucker, R. Pilli, R. Jonsson, A. Camia, C. Thiel, C. Hoyer-Klick, F. D. Longa, T. Kober, J. Badger, P. Volker, B. Elbersen, A. Brosowski, and D. Thrän. Enspreso - an open, eu-28 wide, transparent and coherent database of wind, solar and biomass energy potentials. Energy Strategy Reviews, 26:100379, 2019. ISSN 2211467X. doi: https://doi.org/10.1016/j.esr.2019.100379.

R. E. Sims, W. Mabee, J. N. Saddler, and M. Taylor. An overview of second generation biofuel technologies. Bioresource Technology, 101(6):1570 1580, 2010. ISSN 0960-8524. doi: https://doi.org/10.1016/j.biortech.2009. 11.046.

The European Commission. The Paris Agreement, 2015. URL https://ec. europa.eu/clima/policies/international/negotiations/paris_en.

The European Commission. The European Green Deal, 2019.

The European Commission. Climate strategies and targets, 2020a. URL https: //ec.europa.eu/clima/policies/strategies_en.

The European Commission. Hydrogen, 2020b. URL https://ec.europa.eu/ energy/topics/energy-system-integration/hydrogen_en.

The European Commission. EU strategy on energy system integration, 2020c. URL https://ec.europa.eu/energy/topics/energy-system-integration/ eu-strategy-energy-system-integration_en.

The European Commission. EU strategy on offshore renewable energy, 2020d. URL https://ec.europa.eu/energy/topics/renewable-energy/eustrategy-offshore-renewable-energy_en.

Transport and Environment. How to decarbonize the transport sector by 2050, 2018. URL https://www.transportenvironment.org/sites/te/files/ publications/2018_11_2050_synthesis_report_transport_decarbonisation. pdf.

P. J. H. Volker, A. N. Hahmann, J. Badger, and H. E. Jørgensen. Prospects for generating electricity by large onshore and offshore wind farms. Environmental Research Letters, 12(3):034022, mar 2017. doi: 10.1088/17489326/aa5d86.

F. Wiese and M. Baldini. Conceptual model of the industry sector in an energy system model: A case study for denmark. Journal of Cleaner Production, 203:427 - 443, 2018. ISSN 0959-6526. doi: https://doi.org/10.1016/j. jclepro.2018.08.229.

F. Wiese, R. Bramstoft, H. Koduvere, A. P. Alonso, O. Balyk, J. G. Kirkerud, Åsa Grytli Tveten, T. F. Bolkesjø, M. Münster, and H. Ravn. Balmorel open source energy system model. Energy Strategy Reviews, 20:26 - 34, 2018. ISSN 2211-467X. doi: 10.1016/j.esr.2018.01.003. 